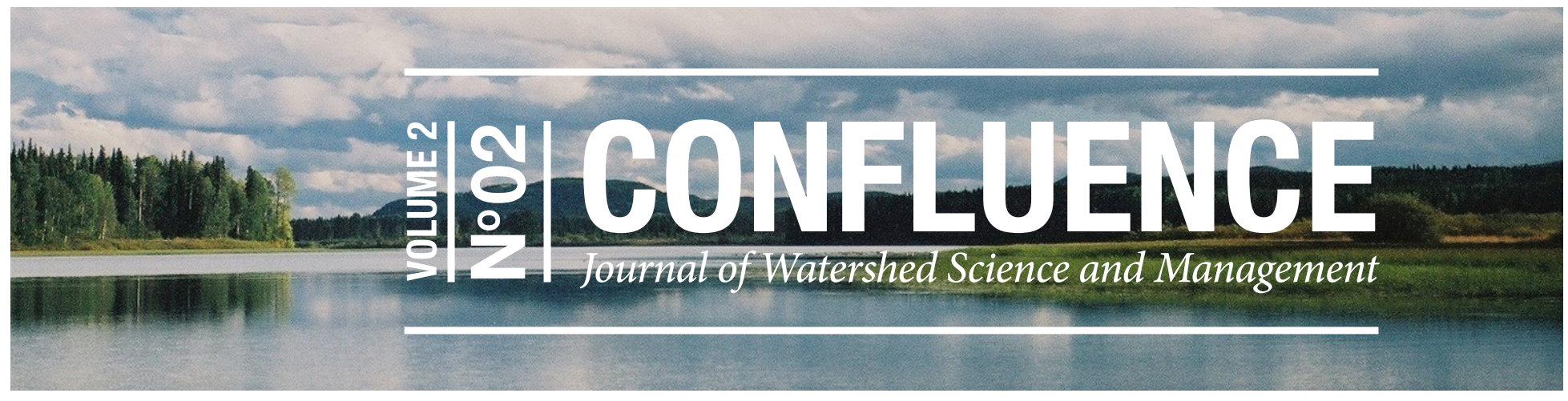

\title{
A Review of Free Optical Satellite Imagery for Watershed-Scalle Landscape Analysis
}

\section{Alexandre Bevington, Hunter Gleason, Xavier Giroux-Bougard, \& Tyler de Jong}

Alexandre Bevington is a Research Earth Scientist for the Ministry of Forests, Lands, Natural Resource Operations and Rural Development, Government of British Columbia and a PhD Candidate in the Natural Resources and Environmental Studies Department, University of Northern British Columbia. Email: alexandre.bevington@gov.bc.ca

Hunter Gleason has a Masters degree in Natural Resources and Environmental Studies, University of Northern British Columbia and is currently a Remote Sensing Research Assistant for the Ministry of Forests, Lands, Natural Resource Operations and Rural Development, Government of British Columbia. Email: hunter.gleason@gov.bc.ca

Xavier Giroux-Bougard is a PhD Candidate currently pursuing research on the movement ecology and landscape ecology of wildlife in the Department of Natural Resource Sciences, McGill University. Email: xavier.girouxbougard@mail.mcgill.ca

Tyler de Jong is a researcher based in Whitehorse, Yukon with Global Water Futures at McMaster University. Email: tyler.dejong@mcmaster.ca

\section{Abstract}

\section{Watershed-scale landscape analysis includes many disciplines, including ecological, hydrological, and geographical sciences. The recent proliferation of free optical satellite imagery (FOSI) has changed the possibilities for the monitoring of environmental change at local and global scales. Many reviews exist for discipline-specific remote sensing applications; however, this article seeks to highlight the rapidly growing archive of FOSI and applied tools that can be used by all levels of users. Herein, ten techniques and eight applications of FOSI are reviewed, along with the specifications and limitations of various sources of FOSI. Although this review focuses on Western Canada, the democratization of FOSI is globally relevant, and the objective is to explain basic concepts via figures and reference materials to help summarize this rapidly changing field.}

KEYWORDS free optical satellite imagery; remote sensing; watershed science; environmental monitoring; open data

\section{Introduction}

Remote sensing is the science of obtaining information about an object from a distance. This information can be collected from terrestrial, aquatic, aerial, or satellite platforms. Optical imaging sensors aboard these platforms record image data consisting of emitted or reflected electromagnetic energy. Since 2008, the availability of free optical satellite imagery (FOSI) has grown exponentially since the United States Geological Survey (USGS) first opened its image archives (Woodcock et al., 2008). As such, the Earth is currently being imaged many times per day at a variety of spatial resolutions (Malenovský et al., 2012; Roy et al., 2014). The availability of FOSI has enabled the development of free online visualization tools (see Appendix A), free open source remote sensing software (see Appendix B), and free analysis-ready remote sensing products (see Appendix C). The abundance of FOSI has empowered natural resource managers, researchers, and others to increase, and ultimately improve, the monitoring and quantification of watershed-scale environmental change.

Review articles have addressed vegetation mapping (Xie et al., 2008), land cover classification (Phiri \& Morgenroth, 2017), forest inventories (White et al., 2016), and large area mapping techniques (Gómez et al., 2016; Hansen \& Loveland, 2012). This article focuses on FOSI and aims to provide an overview 
of: 1) fundamental concepts;2) common datasets; 3) data portals; 4) processing techniques; and 5) applied examples of watershed-scale remote sensing. The objective is to provide readers new to satellite remote sensing with a comprehensive reference guide explained in plain language, and to provide advanced users with a helpful compilation of reference materials.

Fundamental FOSI Concepts
This section provides a synthesis of fundamental concepts in Earth observation (EO) remote sensing science, with a focus on passive optical sensors that measure and record energy emitted from external sources (typically the sun). Earth observation satellites have near-polar sun-synchronous orbits, meaning they pass from north to south, and then south to north again on a slight "near-polar" angle. Their orbits take about 90 minutes to complete and revisit times may take up to 16 days. The viewing angle (aka, look angle) of the satellite sensor can be straight down (nadir), side-looking, back-looking, or front-looking. Most platforms equipped with high-resolution sensors can change their look angle between acquisitions (usually $<20^{\circ}$ from nadir), whereas most FOSI sensors have a fixed look angle (typically nadir). Nadir imagery has the advantage of constant image geometry, whereas imagery acquired at different angles can have distortions, such as seeing different sides of the same object.

While conventional digital cameras record red, green, and blue light to make RGB composite images, optical satellite sensors can record single (panchromatic), multiple (multispectral), or many (hyperspectral) spectral bands. These often include visible (VIS), near infrared (NIR), short-wave infrared (SWIR), and thermal infrared (TIR) wavelengths. High pixel values of these wavelengths indicate a high reflectance and low absorption. Although multispectral bands are used for many purposes; Table 1 lists common interpretations.

Table 1. Common multispectral band names and their interpretations

\begin{tabular}{|l|l|}
\hline Band Name & Common Interpretations \\
\hline Panchromatic & Usually samples visible light at a higher resolution \\
\hline Ultra-Blue & $\begin{array}{l}\text { Shallow water, suspended sediments, chlorophyll concentrations, algae blooms, and aerosols; } \\
\text { also known as the coastal or aerosol band }\end{array}$ \\
\hline Blue & Shallow water, land cover, and deciduous/coniferous, sensitive to atmospheric scatter \\
\hline Green & Emphasizes the true colour of vegetation \\
\hline Red & Discriminates vegetation and chlorophyll absorption for vegetation health \\
\hline Red Edge & Exploits the sharp contrast between red and near infrared \\
\hline NIR & Emphasizes biomass content and shorelines \\
\hline SWIR1 & Soil and canopy moisture and thin cloud penetration \\
\hline SWIR2 & Soil and canopy moisture and thin cloud penetration \\
\hline Cirrus & Detection of cirrus clouds \\
\hline TIR & Thermal mapping, soil moisture, cloud mapping \\
\hline
\end{tabular}

Note: Not all sensors have these bands, and not all bands are in this table. Source: Modified from USGS (2017a) and Geospatial Innovation Facilities (2008).

Satellite images can have high $(<10 \mathrm{~m})$, medium $(10$ to $100 \mathrm{~m})$, or low (>100 m) spatial resolutions, although these definitions can vary. Spatial resolution is often a compromise between the swath (width) of the scene, data storage, and revisit times. For example, high-resolution sensors commonly image a small portion of the Earth, whereas low-resolution sensors commonly view a large portion. Some low-resolution sensors image the entire planet more than once per day, whereas high-resolution sensors change their look angle to rapidly image targeted sites. 
Optical satellite sensors record electromagnetic energy for every pixel of an image. These raw pixel values, known as digital numbers (DN), are unit-less until post-processing corrections are made. The sensitivity of the instrument depends on the radiometric resolution of the sensor. For example, 8-bit radiometry can store $\mathrm{DN}$ values between 0 and 255 (per pixel, per band), whereas higher sensitivity sensors may have 16-bit radiometry and be able to store values between 0 and 65,535 . The wavelength ranges for the same band (e.g., red) often vary between sensors. High spectral resolution sensors have narrow wavelength ranges, whereas lower spectral resolution sensors have wide wavelength ranges, and are thus more difficult to interpret due to wider spectral influences within a given pixel.

Spectral radiance is a physical measurement of electromagnetic radiation that is calculated by applying sensor- and band-specific gain and offset values to DN values. Satellite data providers include these values in the metadata of each image. Top of Atmosphere (TOA) reflectance is another correction that accounts for the source of incoming radiation. However, to best approximate the true reflectance of an object from space, TOA values are corrected for atmospheric distortions using other satellite data or weather models. These corrections estimate surface reflectance (SR) values, which are the best approximation of true surface reflectance properties and should be used in projects that require analysis over time or between sensors.

Since 1958, more than $500 \mathrm{EO}$ and meteorological satellites have been launched into orbit with more coming in the next few decades (World Meteorological Organization, 2016). Only a minority of these satellites provide FOSI that is useful at watershed scales. This section briefly lists commonly used low-, medium-, and high-resolution sources of FOSI.

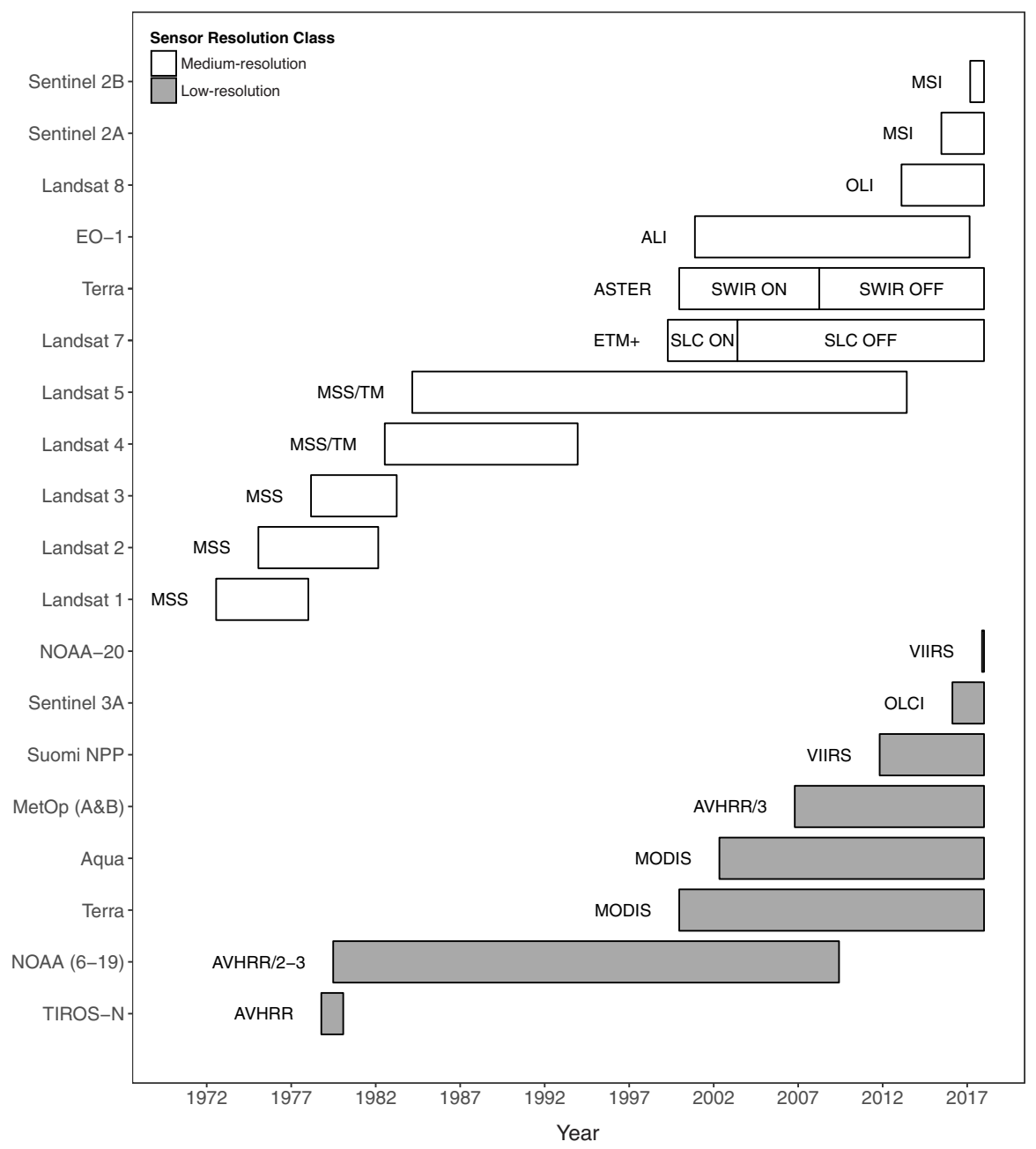

Figure 1. The active lifetimes of EO satellites launched since 1972 and their respective imaging sensors. Light and dark grey boxes represent medium- and low-resolution sensors, respectively. Comments regarding sensor failures are found in the boxes of affected sensors, with additional commentary in Appendix D and Appendix E. 
Continent- or planetary-scale projects requiring daily acquisitions may employ low-resolution FOSI (e.g., global wildfire detection, coarse global land cover, etc.). The most widely used low-resolution sensors are AVHRR 1-3, MODIS, and VIIRS (Figure 1). The AVHRR holds the longest record, though the pair of MODIS sensors offer much higher resolution daily imagery (Lasaponara \& Lanorte, 2012). For more information on these satellite sensors see Appendix D.

Local or watershed-scale projects with sparse temporal acquisitions may employ medium-resolution FOSI (e.g., $30 \mathrm{~m}$ land cover classification, forest health studies, etc.). Six sensors provide the majority of medium-resolution FOSI: Landsat's MSS, TM, ETM+, and OLI sensors, Terra's ASTER sensor, and Sentinel's MSI sensors. Some of these sensors are deployed aboard multiple satellite platforms (Figure 1). In the last few years, Sentinel's MSI sensors have provided a complementary dataset to the Landsat Program with an improved 10-20 m resolution (versus 15-30 m for Landsat) and a five-day repeat interval, though no thermal infrared bands are present (Figure 2).

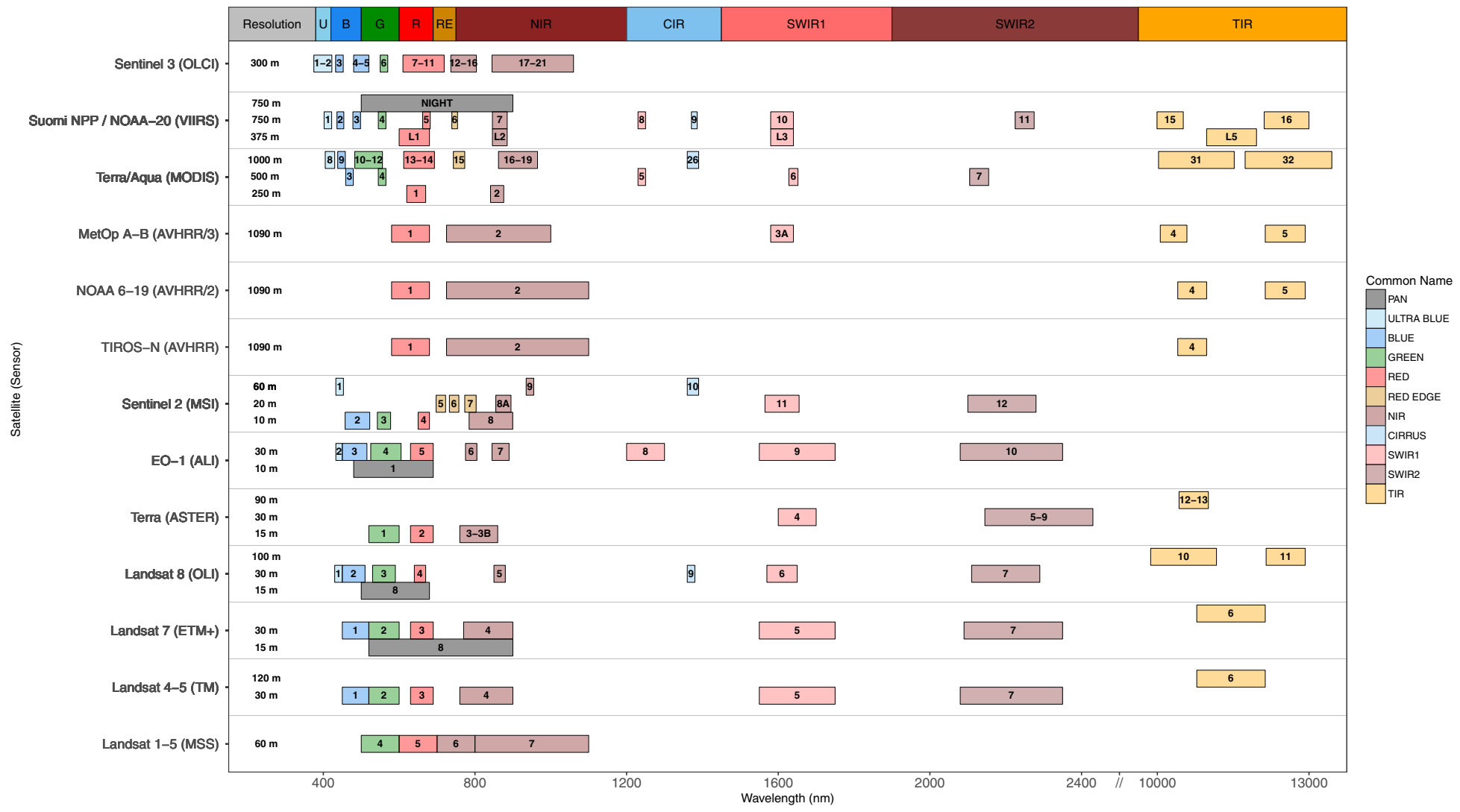

Figure 2. Comparison of bands measured by low-and medium-resolution FOSI satellite sensors. Note: some values have been altered slightly for display purposes; wavelengths between 3,000 and 10,000 $\mathrm{nm}$ have been omitted.

FOSI is increasingly common in watershed-scale landscape analysis, and satellite image archives are becoming easier to access. Figure 3 demonstrates the quantity of medium-resolution FOSI currently available over Vancouver, British Columbia, Canada. More than 2,000 FOSI images have been acquired since 1972, with a notable increase in the last three years. For more information on these satellites and sensors, see Appendix E. While there are currently no sources of high-resolution FOSI, continued trends in sensor technologies and the relative costs of acquisitions suggest this will likely be available in the not too distant future. Meanwhile, free high-resolution data of specific areas of Earth are available through many basemap products (e.g., Google Earth, Bing, and Nokia Here) and through the Planet Explorer (see Appendix A).

Data Portals
Four data portals that provide access to full resolution satellite imagery include: 1) USGS Earth Explorer; 2) European Space Agency (ESA) Copernicus Data Hub; 3) National Oceanic Atmospheric Administration (NOAA) Comprehensive Large Array-Data Stewardship System; and 4) National Aeronautics and Space Administration (NASA) Earthdata Search. The USGS Earth Explorer data portal provides access to imagery from many satellite sensors (United States Geological Survey, 2017a) 


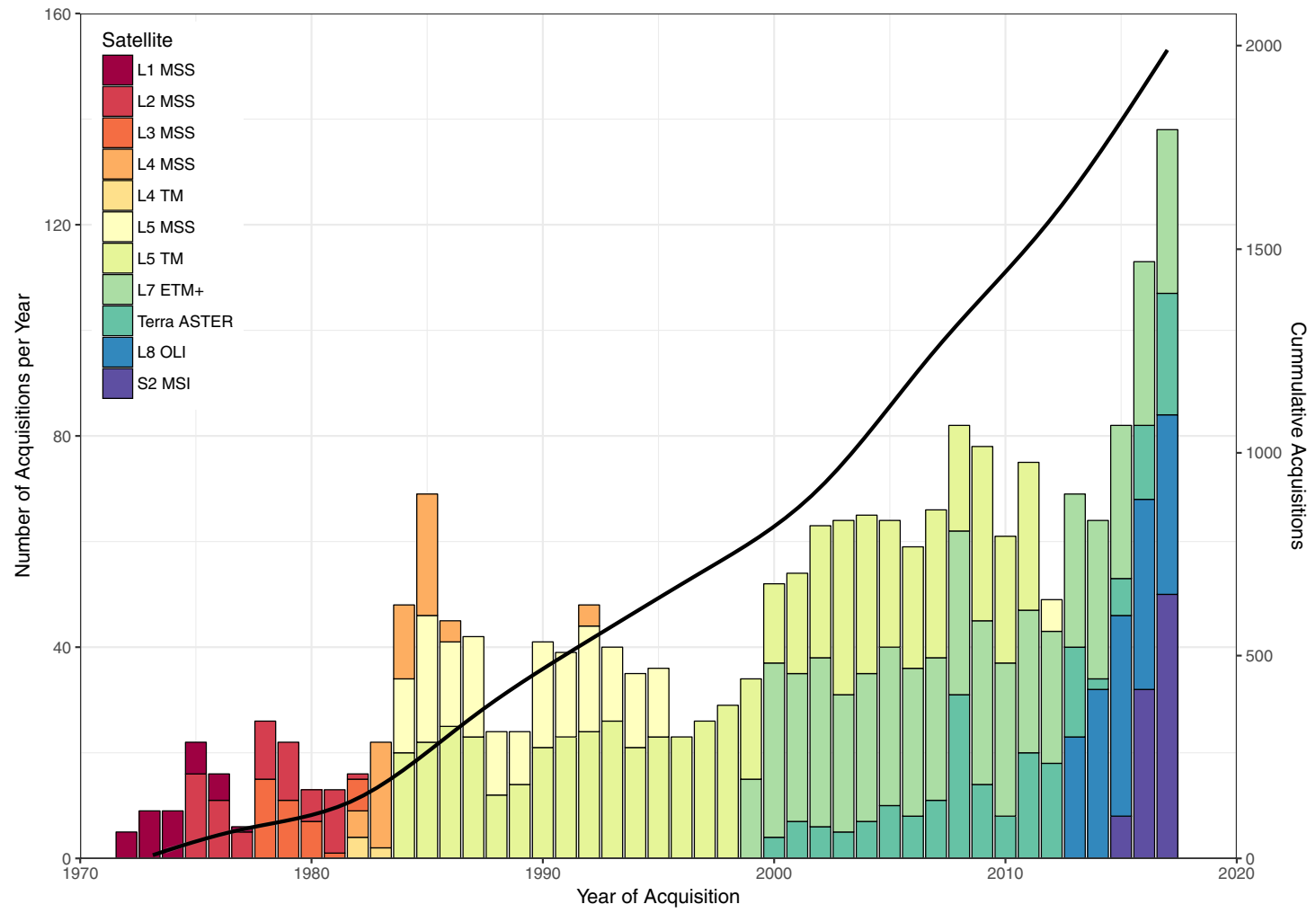

Figure 3. The number of freely available medium-resolution satellite acquisitions per year over Vancouver, British Columbia, Canada $\left(49.24^{\circ} \mathrm{N}, 123.16^{\circ} \mathrm{W}\right)$, and cumulative acquisitions over the same area (black line).

not limited to medium-resolution images from the Landsat, ASTER, EO-1, and Sentinel-2 satellite sensors, and low-resolution images from the MODIS and VIIRS sensors (the USGS [2017c] GloVis portal has similar functionality). The Copernicus Open Access Hub provides access to imagery from the Sentinel-1, -2, and -3 satellites (European Space Agency, 2017a). The Comprehensive Large ArrayData Stewardship System (CLASS) website is an excellent resource for AVHRR and VIIRS imagery (National Oceanic and Atmospheric Administration, 2017a). Earthdata Search is a NASA data portal that provides access to a wide variety of full-resolution imagery. Many satellite datasets are available via more than one data portal, and users tend to develop preferences. The abundance of data available through these portals has sparked the creation of many powerful software tools, such as free online visualization tools (see Appendix A), free open source remote sensing software (see Appendix B), and free analysis-ready remote sensing products (see Appendix C).

The following section is an introduction to common methods used in the transformation of FOSI into analysis-ready products. The following paragraphs summarize techniques for a general audience, but also serve as a collection of references for further reading and a quick-access guide for intermediate users.

\section{Image Geometry}

Georeferencing is the anchoring and re-projection of a spatial dataset to a geographic coordinate system. Satellite data products are generally georeferenced by the provider. In some cases, the georeferencing of a product, especially older datasets, may not be accurate enough for the needs of a project and additional georeferencing is required. Orthorectification is the process of correcting a georeferenced image for distortions caused by the terrain or look angle. A digital elevation model (DEM) or Digital Surface Model (DSM) is required to orthorectify images. The resulting ortho-image will have a constant scale independent of elevation. FOSI are often orthorectified by the data provider. If the imagery resolution is less than the height of an object on the ground, then orthorectification requires a DSM, which accounts for the height irregularities of a topographic surface. 


\section{Composite Imagery}

Satellite images are commonly interpreted with the naked eye with no further computational analysis required. Composite images blend three spectral bands into a single red-green-blue image (RGB) facilitating visual interpretation. Different combinations of bands may lead to different interpretations of the image. Depending on the application or topic of interest, pre-set recommendations of band combinations exist for most satellite sensors (see Table 2). For example, combining bands 7, 5, and 4 (SWIR2, NIR, RED) from Landsat-8 OLI and assigning them to the red-green-blue visualization channels respectively enhances healthy vegetation, which will appear bright green. Healthy vegetation reflects NIR and absorbs the SWIR and RED wavelengths. Pansharpening is a technique that uses higher resolution panchromatic images to cartographically sharpen lower resolution multispectral bands.

Table 2. Common band combinations for the visualization of multispectral composite imagery

\begin{tabular}{|l|l|}
\hline RGB Band Combination & Combination Name \\
\hline RED, GREEN, BLUE & True Colour \\
\hline NIR, RED, GREEN & Near Infrared Vegetation \\
\hline SWIR2, NIR, RED & False Colour Vegetation \\
\hline SWIR1, NIR, BLUE & False Colour Agricultural \\
\hline SWIR2, RED, BLUE & False Colour Geological \\
\hline RED, GREEN, COASTAL & False Colour Bathymetric \\
\hline SWIR2, SWIR1, RED & False Colour Urban \\
\hline
\end{tabular}

Note: Modified from Geospatial Innovation Facilities (2008) and Butler (2013)

\section{Spectral Indices and Ratios}

Spectral indices and ratios are calculations between bands that reveal reflectance properties of objects that may be difficult to see otherwise. Common indices include the normalized difference vegetation index (NDVI) and the normalized difference moisture index (NDMI), but many more exist (see Table 3). The normalization process is a simple yet effective way to enhance band contrasts with a scaled output between -1 and +1 . Spectral indices can be classified using thresholds (e.g., an NDVI greater than 0.4 is generally considered forest). Spectral ratios, or band ratios, can be equally informative when they are applied for the detection of water and land cover types, and often for glacier detection (Table 3). Ratios from different spectral regions enhance important land cover differences (e.g., rock, water, and vegetation), whereas ratios from similar spectral regions enhance subtle land cover differences (e.g., rock type or vegetation type).

\section{Image Transformations}

Two commonly used image transformations are Principal Component Analysis (PCA) and Tasseled Cap transformation (TC). The PCA statistically transforms multispectral imagery into groups of uncorrelated data and discards redundancy in multispectral images (Loughlin, 1991). This technique is image specific and reduces data dimensionality while increasing efficiency when classifying land cover. The TC transformations convert multispectral image bands using validated calibration coefficients that are sensor specific (Table 3). The TC products represent brightness, greenness, and wetness and can be combined in composite images revealing information about land cover (Crist \& Cicone, 1984).

\section{Image Classification}

FOSI can be grouped into classes based on spectral and geometric properties. Classification methods can be unsupervised, supervised, or object-oriented (Phiri \& Morgenroth, 2017). Unsupervised classification techniques group pixels based on similar spectral values with limited user input. Parametric (e.g., K-means, ISO) and non-parametric (e.g. random forests, neural networks) clustering algorithms can be used in unsupervised classification. These require cautious interpretation, and they are best suited for areas where little is known about the ground conditions. Alternatively, supervised classifications rely on user input data, where users define classes of interest and the software classifies similar pixels using spectral statistics (e.g., maximum likelihood, minimum distance). Supervised classification 
Table 3. Selected spectral indices and ratios with formulas

\begin{tabular}{|c|c|c|}
\hline Index or Ratio & Formula & $\begin{array}{l}\text { Description and Original } \\
\text { Reference }\end{array}$ \\
\hline $\begin{array}{l}\text { Normalized Difference } \\
\text { Vegetation Index }\end{array}$ & $N D V I=\frac{N-R}{N+R}$ & $\begin{array}{l}\text { Vegetation and biomass index } \\
\text { (Rouse et al., 1973) }\end{array}$ \\
\hline $\begin{array}{l}\text { Normalized Difference } \\
\text { Water Index }\end{array}$ & $N D W I=\frac{G-N}{G+N}$ & $\begin{array}{l}\text { Water body index } \\
\text { (McFeeters, 1996) }\end{array}$ \\
\hline $\begin{array}{l}\text { Modified Normalized } \\
\text { Difference Water Index }\end{array}$ & $m N D W I=\frac{G-S 1}{G+S 1}$ & $\begin{array}{l}\text { Improved water body index } \\
(\mathrm{Xu}, 2006)\end{array}$ \\
\hline $\begin{array}{l}\text { Automated Water } \\
\text { Extraction Index }\end{array}$ & $A W E I_{n s h}=4 \cdot(\mathrm{G}-\mathrm{S} 1)-0.25 \cdot N+2.75 \cdot S 2$ & $\begin{array}{l}\text { Improved water body index } \\
\text { (Feyisa et al., 2014) }\end{array}$ \\
\hline $\begin{array}{l}\text { Normalized Difference } \\
\text { Moisture Index }\end{array}$ & $N D M I=\frac{N-S 1}{N+S 1}$ & $\begin{array}{l}\text { Canopy and soil moisture index } \\
(\text { Gao, 1996) }\end{array}$ \\
\hline Normalized Burn Ratio & $N B R=\frac{N-S 2}{N+S 2}$ & $\begin{array}{l}\text { Burn severity index } \\
\text { (Key \& Benson, 1999) }\end{array}$ \\
\hline $\begin{array}{l}\text { Differenced Normalized } \\
\text { Burned Ratio }\end{array}$ & $d N B R=N B R_{P R E}-N B R_{P O S T}$ & $\begin{array}{l}\text { NBR relative to pre-fire } \\
\text { conditions (Key \& Benson, 2006) }\end{array}$ \\
\hline $\begin{array}{l}\text { Normalized Difference } \\
\text { Snow Index }\end{array}$ & $N D S I=\frac{G-S 1}{G+S 1}$ & Snow index (Hall et al., 1995) \\
\hline $\begin{array}{l}\text { Enhanced Vegetation } \\
\text { Index }\end{array}$ & $E V I=2.5\left(\frac{N-R}{1+N+6 \cdot R-7.5 \cdot B}\right)$ & $\begin{array}{l}\text { Enhanced vegetation index } \\
\text { (Huete et al., 1997) }\end{array}$ \\
\hline Tasseled Cap Wetness & $T C W=B \cdot B_{C}+G \cdot G_{C}+R \cdot R_{C}+N \cdot N_{C}+S 1 \cdot S 1_{C}-S 2 \cdot S 2_{C}$ & $\begin{array}{l}\text { Pixel wetness } \\
\text { (Crist \& Cicone, 1984) }\end{array}$ \\
\hline Tasseled Cap Greenness & $T C G=B \cdot B_{C}-G \cdot G_{C}-R \cdot R_{C}-N \cdot N_{C}+S 1 \cdot S 1_{C}-S 2 \cdot S 2_{C}$ & $\begin{array}{l}\text { Pixel greenness } \\
\text { (Crist \& Cicone, 1984) }\end{array}$ \\
\hline Tasseled Cap Brightness & $T C B=B \cdot B_{C}+G \cdot G_{C}+R \cdot R_{C}+N \cdot N_{C}+S 1 \cdot S 1_{C}-S 2 \cdot S 2_{C}$ & $\begin{array}{l}\text { Pixel brightness } \\
\text { (Crist \& Cicone, 1984) }\end{array}$ \\
\hline Disturbance Index & $D I=T C B_{R}-\left(T C G_{R}+T C W_{R}\right)$ & $\begin{array}{l}\text { Forest disturbance mapping } \\
\text { (Healey et al., 2005) }\end{array}$ \\
\hline Red Green Index & $R G I=R / G$ & $\begin{array}{l}\text { Detection of red attack trees } \\
\text { (Coops et al., 2006) }\end{array}$ \\
\hline Red Band Ratio & $R R=N / R$ & $\begin{array}{l}\text { Forest, water, and cropland } \\
\text { (Jordan, 1969) }\end{array}$ \\
\hline Glacier Band Ratio & $G R=N / S 1$ & $\begin{array}{l}\text { Glacier area delineation } \\
\text { (Hall et al., 1987) }\end{array}$ \\
\hline
\end{tabular}

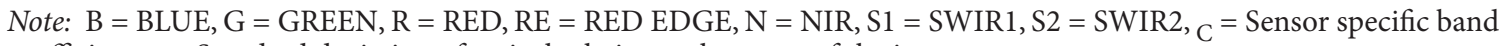
coefficient, ${ }_{R}=$ Standard deviation of a pixel relative to the mean of the image

requires knowledge of ground conditions or higher resolution data to identify the classes of interest. Object-oriented (or object-based) image analysis uses spectral and contextual metrics of predefined spatial groupings/clusters (Heurich et al., 2010). Object classes are derived from the shape, size, value range, and texture of pixel groupings/clusters.

\section{Change Detection}

Change detection is achieved using time-separated imagery (Hansen \& Loveland, 2012). Manual flickering or swiping between images in a geographic information system (GIS) environment can often lead to qualitative interpretations of change for the occasional user or for inter-sensor comparison. Other techniques detect change between images and classify the results semi-automatically. For example, two NDVI images can be differenced to identify forest gain or loss. Other change-detection methods could focus on the changes of land cover classes between images.

\section{Time-Series Analysis}

With dense time-separated images, or stacks, time-series analysis can efficiently represent trends over large areas. Regression analysis, harmonic functions, and residual functions can represent the annual, seasonal, and day-month variations of a dataset (Kuenzer et al., 2015). Calculating time-series statistics 
over an image stack can demand a large amount of computation, though with new tools (e.g., Google Earth Engine) time-series analysis over large areas has become much more feasible for users (Gorelick et al., 2017). For example, by plotting a time series of NDVI values over a region downstream of the 2014 Mount Polley mining incident in British Columbia, Canada, forest cover removal becomes evident when the seasonal cycle of Landsat 8 OLI derived NDVI values is removed (Figure 4).

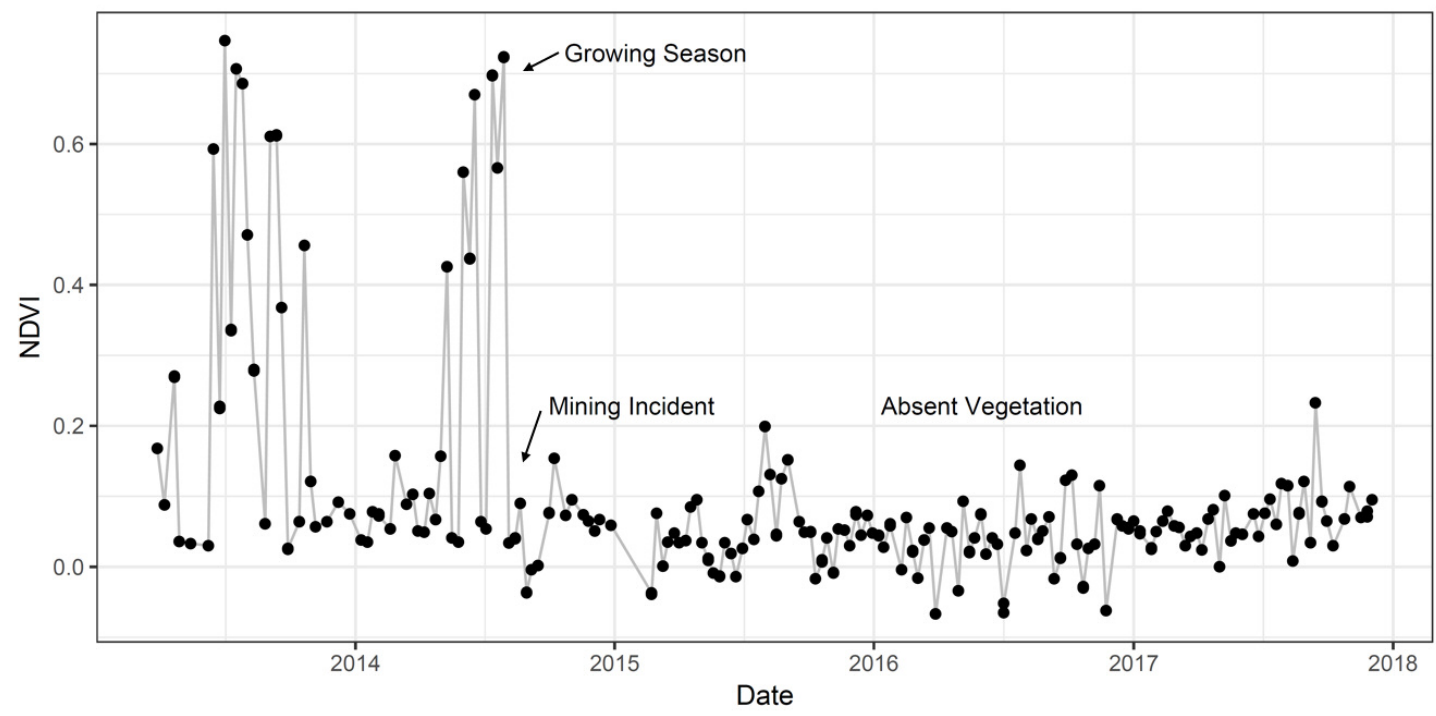

Figure 4. Time-series analysis of Landsat 8 OLI NDVI values for the downstream area affected by the Mount Polley mining spill near Likely, British Columba $\left(52.53^{\circ} \mathrm{N}, 121.59^{\circ} \mathrm{W}\right)$. This plot demonstrates that the period from 2013-2014 has a seasonal fluctuation of NDVI values indicating strong vegetation, such as a forest. During the 2014 calendar year, the forest was destroyed by a mining incident, and the vegetation has yet to recover.

\section{Optically Derived Digital Elevation Models}

FOSI from two or more different look angles can be combined to create a DEM of the visible surface of the Earth, including objects that obstruct the ground (Toutin, 2001). For example, the ASTER sensor, onboard the Terra satellite, captures both nadir and back-looking images, allowing the computation of DEMs from every repeat pass. ASTER DEMs have been combined as a free global $30 \mathrm{~m}$-resolution DEM (Tachikawa et al., 2011). More recently, high-resolution optical stereo imagery from high-resolution satellite sensors have been used to create free high-resolution DEMs using free stereogrammetry software (Intelligent Robotics Group, 2017) for many areas of the circumpolar Arctic (Polar Geospatial Center, 2017) and Himalaya (Shean, 2017) regions.

\section{Velocity Measurement}

Objects (rocks, slopes, or identifiable features) that move between time-separated images can be tracked using manual or automatic methods. Automated approaches use statistical methods to match pixels within a search neighbourhood to create velocity vectors. For instance, the velocity of river ice on the Mackenzie River was measured to an accuracy of $\sim 0.07 \mathrm{~m} / \mathrm{s}$ using near-simultaneous image acquisitions (Beltaos \& Kääb, 2014). Pixel-tracking software packages have been developed, for example IMCORR (Scambos et al., 1992), CIAS (Kääb \& Vollmer, 2000), VisiCORR (Dowdeswell \& Benham, 2003), and COSI-Corr (Leprince et al., 2007).

\section{Cloud-Free Mosaics}

Identifying and removing clouds from multispectral optical imagery is an important task, especially for the creation of cloud-free mosaics. Most cloud-masking algorithms have difficulty over bright targets, such as beaches, snow, and ice (e.g., Foga et al., 2017; Zhu et al., 2015). Best-available-pixel (BAP) techniques filter images for a single pixel using the day of the year, cloud cover, and other parameters to select the ideal pixel to use in a mosaic (Hermosilla et al., 2015a, 2016; White et al., 2014). Other techniques do not attempt to choose a best pixel but rather calculate a pixel-value statistic (e.g., mean, minimum, etc.) based on a stack of candidate images. 
FOSI has many applications in watershed-scale landscape analysis. Raw or calibrated imagery (e.g., $\mathrm{DN}, \mathrm{TOA}, \mathrm{SR})$, and analysis-ready products provide information about the landscape. For example, interpretations of the same image as a true colour, NIR false colour, and SWIR false colour composite may differ (Figure 5, A-B). This section provides an overview of applied examples of watershed-scale remote sensing.

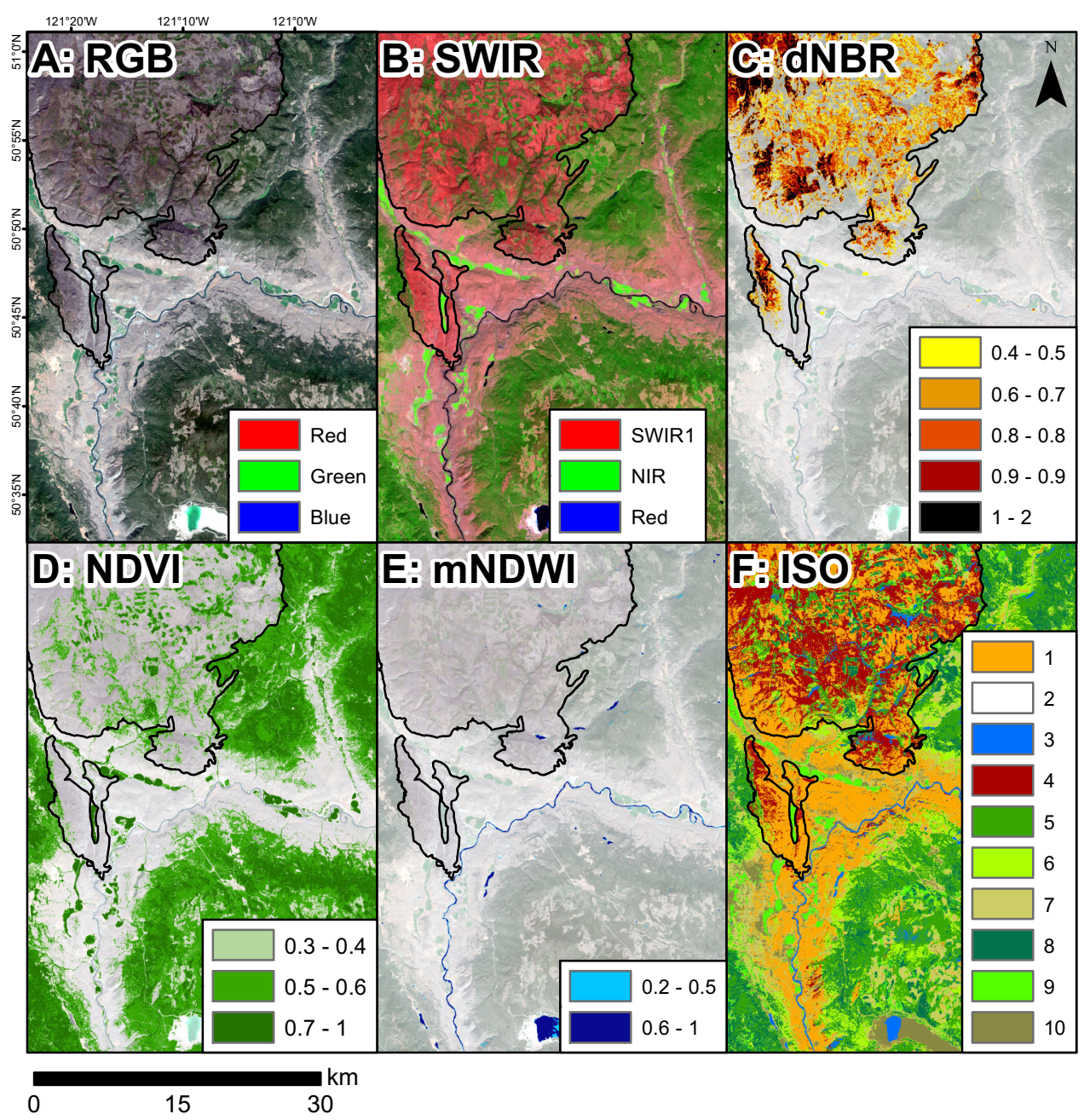

Figure 5. Landsat 8 OLI imagery near Cache Creek, British Columbia, acquired September 12, 2017. The upper left of the image is the Elephant Hill wildfire (black outline) and the main river is the Thompson River. A) True colour ( $R, G, B)$ composite. B) False colour (SWIR1, NIR, $R)$ composite. C) Differenced normalized burn ratio (dNBR), where higher values indicate greater burn intensities. D) Normalized difference vegetation index (NDVI), where values greater than 0.4 are highly productive vegetation. E) Modified normalized difference water index (mNDWI) to extract water outlines. F) ISO unsupervised classification into 10 classes.

\section{Wildfire}

Many low-resolution satellites have thermal-anomaly products to identify active wildfires around the world. MODIS Terra and Aqua (Justice et al., 2002; Kaufman et al., 1998) and Suomi NPP VIIRS (Schroeder et al., 2014) are commonly used for wildfire detection. The Sentinel-3A SLSTR sensor has demonstrated utility for this application (Wooster et al., 2012). Limitations include cloud cover, low spatial resolution, and the timing of image acquisition. The Normalized Burn Ratio (NBR) and other techniques are operationally used to map fire perimeters, fire intensity, and unburned fuels within a fire boundary (Figure 5,C). Medium-resolution satellites are often used to map the fire boundary and burn intensity at higher spatial and temporal resolutions (Hawbaker et al., 2017).

\section{Forest}

Generally, the NDVI is a good first approximation for forest cover mapping (Figure 5, D). Most notably, global forest cover change has been mapped from Landsat TM, ETM+, and OLI imagery for the period 
of 2000 to 2016 at $30 \mathrm{~m}$ resolution (see Appendix C). The freely available Global Forest Change product over British Columbia (Hansen et al., 2013), indicates a total of $85,900 \mathrm{~km}^{2}$ has been lost (including wildfire and forestry) and $43,800 \mathrm{~km}^{2}$ has been gained, for a net forest cover change of $-42,100 \mathrm{~km}^{2}$ between 2000 and 2015. Forest disturbance, change attribution, and recovery mapping are common applications of FOSI (Hermosilla et al., 2015b; Zhao et al., 2016; Zhu et al., 2012). Researchers have also endeavoured to associate changes in forest health to changes observed across the spectrum of satellitebased remote sensing wavelengths (Meng et al., 2016). Recent studies have shown evidence for the accurate mapping of grey- (Hart \& Veblen, 2015) and green- (Foster et al., 2017) attack spruce stands using spectral indices, while others have shown evidence for the use of thermal remote sensing (Hais \& Kučera, 2008). Remaining challenges for FOSI include tree species identification, canopy height models, and forest density and volume measurements.

\section{Water}

Because of the importance of freshwater on Earth, there have been considerable efforts to map water bodies over large areas and track changes over time (Donchyts et al., 2016; Pekel et al., 2016). While synthetic aperture radar (SAR) sensors are particularly well suited for the rapid mapping of water (e.g., during floods), FOSI can also be leveraged to map surface water extents (Xu, 2006). For instance, the mNDWI provides a simple delineation of water bodies (Figure 5, E) with values generally greater than 0.4. Limitations include the mapping of smaller, turbid, seasonal, and shaded water bodies. FOSI can also be used to map water during floods in ideal cloud-free imaging conditions (Olthof, 2017). Other useful applications include the tracking of water quality, such as the mapping of algae blooms and chlorophyll in lakes (Brezonik et al., 2005) and oceans (Hu, 2009), cyanobacteria (Page et al., 2018), turbidity in small lakes (Lacaux et al., 2007), and the bathymetry of shallow clear waters (Knudby et al., 2016).

\section{Wetlands}

Advanced techniques such as SAR-Optical fusion (Bourgeau-Chavez et al., 2015), Classification Tree Analysis (CTA), and Stochastic Gradient Boosting (SGB) (Baker et al., 2006) have shown success in mapping wetlands. However, mainly due to their seasonal variability, manual interpretation may be favoured for small areas using TC transformations (Fickas et al., 2016). Object-oriented image analysis has shown to have high accuracy for detecting wetlands larger than two acres (Frohn et al., 2009).

\section{Snow and Ice}

Mapping glaciers, snow-covered area, and other cryospheric parameters can be done from multispectral optical data for local (e.g., Bevington \& Copland, 2014) or regional studies (Bolch et al., 2010; Kääb et al., 2010). Landsat GoLive is a freely available global glacier velocity dataset (National Snow and Ice Data Center, 2017). Snowline elevation can be calculated from FOSI (Parajka et al., 2010) and used for hydrological and ecological applications (Verbyla et al., 2017). Using FOSI, long-term changes in cyclical (seasonal) ice events can be monitored for freshwater lakes to understand climate-related changes occurring within watersheds and their ecosystems (Brown \& Duguay, 2012; Latifovic \& Pouliot, 2007).

\section{Thermal Imagery}

Satellite systems such as Landsat, MODIS, and ASTER are outfitted with TIR sensors, which collect TOA radiance. These measurements are the result of emitted radiance from the Earth's surface and radiance fluxes from the atmosphere (Weng, 2009). In order to obtain land surface temperatures (LST), corrections must be made, and Plank's Law must be used to convert radiance values to brightness temperatures (Schmugge et al., 1998). On Landsat 8, bands 10 and 11 are TIR bands, which measure LST at $100 \mathrm{~m}$ resolution, however, they are resampled to $30 \mathrm{~m}$ to match the other multispectral bands. Due to the longer wavelength of the thermal infrared bands, atmospheric scattering is less influential, and imagery can be acquired at night. These TIR bands are used to study trends in Earth surface temperatures, identify wildfires and thermal anomalies, investigate cold-air drainage, and track water temperatures.

\section{Soil Moisture and Drought}

Advances in EO technology have provided substantial improvements in the ability to map soil moisture over the past several decades, particularly soil moisture retrieval from microwave observations (not FOSI), such as the low resolution Soil Moisture Active Passive (SMAP) and the Soil Moisture and Ocean Salinity (SMOS) sensors (Peng \& Loew, 2017). In terms of FOSI, a linear relationship exists between SWIR reflectance and soil moisture $\left(r^{2}=0.698\right.$, Sadeghi et al., 2017). Other studies indicated that the SWIR reflectance is sensitive to vegetation water content (Yilmaz et al., 2008). 


\section{Land Cover}

Land cover classification was one of the earliest uses of satellite imagery (e.g., Anderson et al., 1976;

Figure 5, F) and multiple classification techniques are available (Phiri \& Morgenroth, 2017). The evolution of land cover over time is a topic of extensive research (Zhu \& Woodcock, 2014). Habitat suitability and change is an important application of optical imagery in the field of ecology (e.g., Hansen et al., 2001). Natural hazards and geohazards, such as landslides and earthquakes, can also be mapped from satellite imagery (Kargel et al., 2016).

\section{Conclusion}

The watershed-scale research community has embraced the integration of FOSI. Figure 6 shows academic publications with key satellite sensors in the research article title (Web of Knowledge, 2017). In this Figure, publications in the 70s and 80s are low $\left(<100 \mathrm{y}^{-1}\right)$, whereas the trend in publications since then is nearly exponential. In 2016, the total exceeds 3,000 peer-reviewed publications.

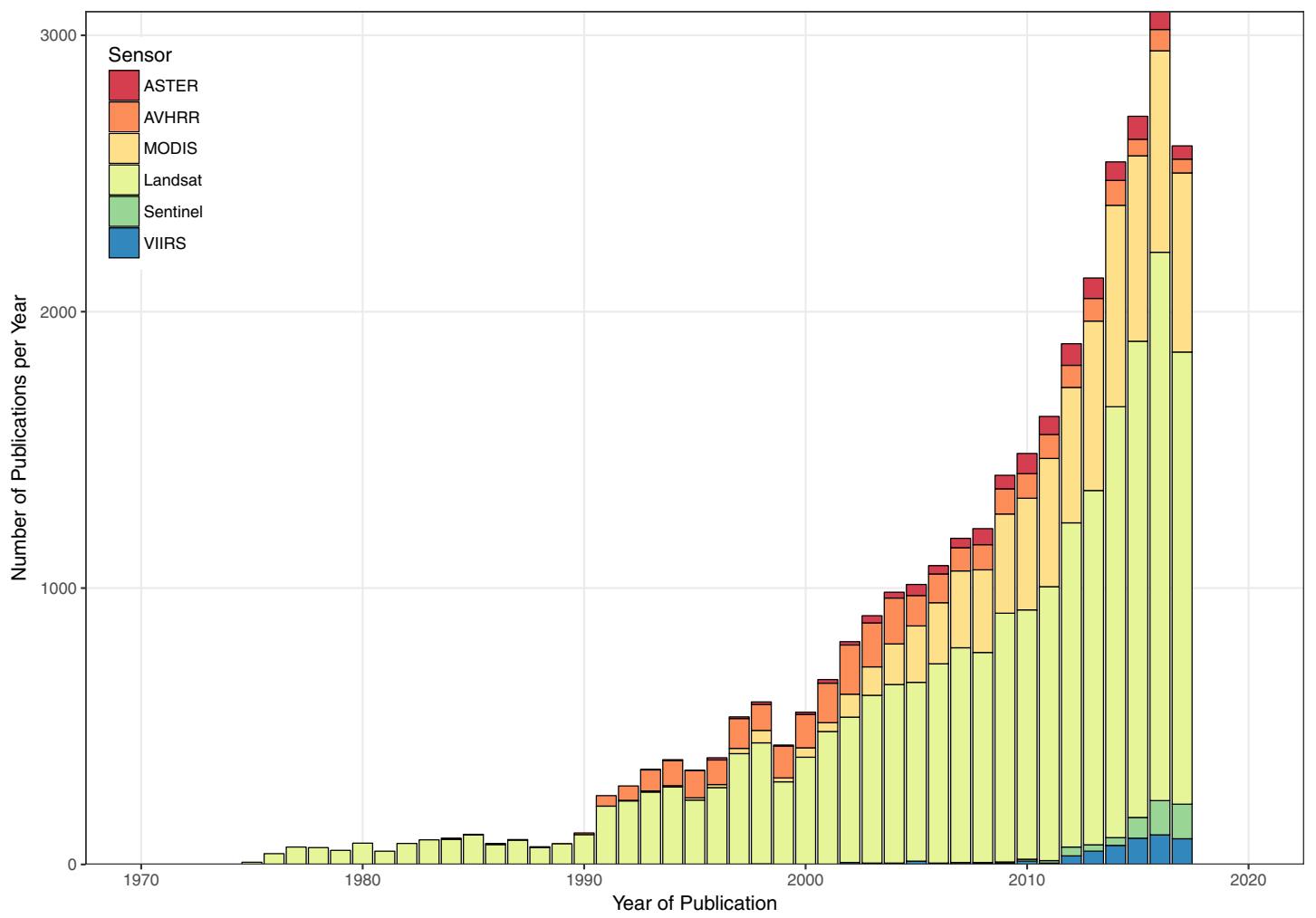

Figure 6. The number of academic publications per year with the common name for the satellite sensor in the title (Web of Knowledge, 2017)

It is in the context of the rapid democratization of satellite remote sensing that this article seeks to bridge academic literature for applied watershed-scale landscape analysts and serve as a compendium, or starting point, for the effective application of FOSI. This article summarizes the fundamental concepts of FOSI applied in watershed-scale analysis at low- and medium-resolutions; describes commonly used data sources and data portals; explains many FOSI processing techniques; and summarizes a variety of applied examples for watershed-scale analysis. Although cloud cover, night, smoke, steep terrain, atmospheric absorption, and other obstructions hinder FOSI, an understanding of these specifications and limitations enables the implementation of FOSI in combination with other methods (e.g., fieldwork, modelling, aerial remote sensing). Above all, applied satellite remote sensing requires the union of operational needs with appropriate FOSI products and techniques. Despite the far reaching benefits of FOSI, dicussions of returning to a for-profit system persists in the USGS (Popkin, 2018).

The authors would like to thank Robin Pike for his enthusiasm and editorial insights throughout the development of this manuscript, as well as the three anonymous reviewers who provided careful edits that greatly improved the accuracy, clarity, and flow of the manuscript. Finally, the authors express sincere gratitude to the providers of free optical satellite imagery and the developers of free and open source remote sensing software for their thankless efforts, which this review merely describes. 
Anderson, J.R., E.E. Hardy, J.T. Roach, \& R.E. Witmer. 1976. A land use and land cover classification system for use with remote sensor data. United States Geological Survey Professional Paper 964. Washington, DC: United States Goverment Printing Office.

Baker, C., R. Lawrence, C. Montagne, \& D. Patten. 2006. Mapping wetlands and riparian areas using Landsat ETM+ imagery and decision-tree-based models. Wetlands, 26(2): 465-474. doi: 10.1672/0277-5212(2006)26[465:MWARAU]2.0.CO;2

Beltaos, S., \& A. Kääb. 2014. Estimating river discharge during ice breakup from near-simultaneous satellite imagery. Cold Regions Science and Technology, 98: 35-46. doi: 10.1016/j.coldregions .2013 .10 .010

Bevington, A., \& L. Copland. 2014. Characteristics of the last five surges of Lowell Glacier, Yukon, Canada, since 1948. Journal of Glaciology, 60(219): 113-123. doi: 10.3189/2014jog13j134

Bolch, T., B. Menounos, \& R. Wheate. 2010. Landsat-based inventory of glaciers in western Canada, 1985-2005. Remote Sensing of Environment, 114(1): 127-137. doi: 10.1016/j.rse.2009.08.015

Bourgeau-Chavez, L., S. Endres, M. Battaglia, M.E. Miller, E. Banda, Z. Laubach, P. Higman, P. ChowFraser, \& J. Marcaccio. 2015. Development of a bi-national Great Lakes coastal wetland and land use map using three-season PALSAR and Landsat imagery. Remote Sensing, 7(7): 8655-8682. doi: $10.3390 /$ rs70708655

Brezonik, P., K.D. Menken, \& M. Bauer. 2005. Landsat-based remote sensing of lake water quality characteristics, including chlorophyll and colored dissolved organic matter (CDOM). Lake and Reservoir Management, 21(4): 373-382. doi: 10.1080/07438140509354442

Brown, L.C., \& C.R. Duguay. 2012. Modelling lake ice phenology with an examination of satellitedetected subgrid cell variability. Advances in Meteorology, 2012: 1-19. doi: 10.1155/2012 /529064

Butler, K. 2013. Band combinations for Landsat 8. URL: https://blogs.esri.com/esri/arcgis/2013 /07/24/band-combinations-for-landsat-8/ (Accessed December 1, 2017).

Carnegie Mellon Create Lab. (n.d.). Time Machine. URL: http://timemachine.cmucreatelab.org /wiki/earthenginetoureditor (Accessed June 5, 2018).

Chen, J., J. Chen, A. Liao, X. Cao, L. Chen, X. Chen, C. He, G. Han, S. Peng, M. Lu, W. Zhang, X. Tong, \& J. Mills. 2015. Global land cover mapping at $30 \mathrm{~m}$ resolution: A POK-based operational approach. ISPRS Journal of Photogrammetry and Remote Sensing, 103: 7-27. doi: 10.1016 /j.isprsjprs.2014.09.002

Christophe, E., J. Inglada, \& A. Giros. 2008. Orfeo toolbox: a complete solution for mapping from high resolution satellite images. The International Archives of the Photogrammetry, Remote Sensing and Spatial Information Sciences, XXXVI(Part B4): 1263-1268.

Congedo, L. 2017. Semi-Automatic Classification Plugin Documentation, Release 5.3.6.1. doi: 10.13140 /rg.2.2.29474.02242/1

Conrad, O., B. Bechtel, M. Bock, H. Dietrich, E. Fischer, L. Gerlitz, J. Wehberg, V. Wichmann, \& J. Böhner. 2015. System for Automated Geoscientific Analyses (SAGA) v. 2.1.4. Geoscientific Model Development, 8(7): 1991-2007. doi: 10.5194/gmd-8-1991-2015

Coops, N.C., M. Johnson, M.A. Wulder, \& J.C. White. 2006. Assessment of Quickbird high spatial resolution imagery to detect red-attack damage due to mountain pine beetle infestation. Remote Sensing of Environment, 103(1): 67-80. doi: 10.1016/j.rse.2006.03.012

Crist, E.P., \& R.C. Cicone. 1984. A physically-based transformation of thematic mapper data-the TM tasseled cap. IEEE Transactions on Geoscience and Remote Sensing, GE-22(3): 256-263. doi: $10.1109 /$ tgrs.1984.350619

Donchyts, G., F. Baart, H. Winsemius, N. Gorelick, J. Kwadijk, \& N. van de Giesen. 2016. Earth's surface water change over the past 30 years. Nature Climate Change, 6(9): 810-813. doi: 10.1038/nclimate 3111

Dowdeswell, J.A., \& T.J. Benham. 2003. A surge of Perseibreen, Svalbard, examined using aerial photography and ASTER high resolution satellite imagery. Polar Research, 22(2): 373-383. doi: 10.3402/polar.v22i2.6466 
European Space Agency. 2018a. Sentinel Hub Playground. URL: http://apps.sentinel-hub.com /sentinel-playground (Accessed June 5, 2018).

European Space Agency. 2018b. EO Browser. URL: https://apps.sentinel-hub.com/eo-browser/ (Accessed June 5, 2018).

European Space Agency. 2017a. Copernicus Open Access Hub. URL: https://scihub.copernicus.eu /dhus/ (Accessed December 1, 2017).

European Space Agency. 2017b. SNAP Toolbox. URL: step.esa.int/ (Accessed December 1, 2017).

Feyisa, G.L., H. Meilby, R. Fensholt, \& S.R. Proud. 2014. Automated Water Extraction Index: A new technique for surface water mapping using Landsat imagery. Remote Sensing of Environment, 140: 23-35. doi: 10.1016/j.rse.2013.08.029

Fickas, K.C., W.B. Cohen, \& Z. Yang. 2016. Landsat-based monitoring of annual wetland change in the Willamette Valley of Oregon, USA from 1972 to 2012. Wetlands Ecology and Management, 24(1): 73-92. doi: 10.1007/s11273-015-9452-0

Foga, S., P.L. Scaramuzza, S. Guo, Z. Zhu, R.D. Dilley, T. Beckmann, G.L. Schmidt, J.L. Dwyer, M. Joseph Hughes, \& B. Laue. 2017. Cloud detection algorithm comparison and validation for operational Landsat data products. Remote Sensing of Environment, 194: 379-390. doi: 10.1016/j.rse.2017.03.026

Foster, A.C., J.A. Walter, H.H. Shugart, J. Sibold, \& J. Negron. 2017. Spectral evidence of early-stage spruce beetle infestation in Engelmann spruce. Forest Ecology and Management, 384: 347-357. doi: 10.1016/j.foreco.2016.11.004

Frohn, R.C., M. Reif, C. Lane, \& B. Autrey. 2009. Satellite remote sensing of isolated wetlands using object-oriented classification of Landsat-7 data. Wetlands, 29(3): 931-941. doi: 10.1672/08-194.1

Gao, B.C. 1996. NDWI - A Normalized Difference Water Index for remote sensing of vegetation liquid water from space. Remote Sensing of Environment, 58(3): 257-266. doi: 10.1016/s0034 $-4257(96) 00067-3$

Geospatial Innovation Facilities. 2008. Landsat spectral band information. URL: http://gif.berkeley .edu/documents/Landsat\%20Band\%20Information.pdf (Accessed December 1, 2017).

Gómez, C., J.C. White, \& M.A. Wulder. 2016. Optical remotely sensed time series data for land cover classification: A review. ISPRS Journal of Photogrammetry and Remote Sensing, 116: 55-72. doi: 10.1016/j.isprsjprs.2016.03.008

Google. (2018a). Google Earth Engine Explorer. URL: https:/explorer.earthengine.google.com (Accessed June 5, 2018).

Google. (2018b). Google Earth Engine Timelapse. URL: https://earthengine.google.com/timelapse/ (Accessed June 5, 2018).

Gorelick, N., M. Hancher, M. Dixon, S. Ilyushchenko, D. Thau, \& R. Moore. 2017. Google Earth Engine: Planetary-scale geospatial analysis for everyone. Remote Sensing of Environment, 202: 18-27. doi: 10.1016/j.rse.2017.06.031

Hais, M., \& T. Kučera. 2008. Surface temperature change of spruce forest as a result of bark beetle attack: Remote sensing and GIS approach. European Journal of Forest Research, 127(4): 327-336. doi: $10.1007 / \mathrm{s} 10342-008-0208-8$

Hall, D.K., J. Ormsby, R. Bindschadler, \& H. Siddalingaiah. 1987. Characterization of snow and ice reflectance zones on glaciers using Landsat Thematic Mapper data. Annals of Glaciology, 9: 104-108. doi: 10.3189/s0260305500000471

Hall, D.K., G.A. Riggs, \& V.V. Salomonson. 1995. Development of methods for mapping global snow cover using moderate resolution imaging spectroradiometer data. Remote Sensing of Environment, 54(2): 127-140. doi: 10.1016/0034-4257(95)00137-p

Hansen, M.C., R. Defries, J.R.G. Townshend, \& R. Sohlberg. 2000. Global land cover classification at $1 \mathrm{~km}$ spatial resolution using a classification tree approach. International Journal of Remote Sensing, 21(6): 1331-1364. doi: 10.1080/014311600210209

Hansen, M.C., \& T.R. Loveland. 2012. A review of large area monitoring of land cover change using Landsat data. Remote Sensing of Environment, 122: 66-74. doi: 10.1016/j.rse.2011.08.024 
Hansen, M.C., P.V. Potapov, R. Moore, M. Hancher, S.A. Turubanova, A. Tyukavina, D. Thau, S.V. Stehman, S.J. Goetz, T.R. Loveland, A. Kommareddy, A. Egorov, L. Chini, C.O. Justice, \& J.R.G. Townshend. 2013. High-resolution global maps of 21st-century forest cover change. Science, 342(6160): 850-853. doi: 10.1126/science. 1244693

Hansen, M.J., S.E. Franklin, C. Woudsma, \& M. Peterson. 2001. Forest structure classification in the North Columbia mountains using the Landsat TM Tasseled Cap wetness component. Canadian Journal of Remote Sensing, 27(1): 20-32. doi: 10.1080/07038992.2001.10854916

Hart, S.J., \& T.T. Veblen. 2015. Detection of spruce beetle-induced tree mortality using high- and medium-resolution remotely sensed imagery. Remote Sensing of Environment, 168: 134-145. doi: 10.1016/j.rse.2015.06.015

Hawbaker, T.J., M.K. Vanderhoof, Y.J. Beal, J.D. Takacs, G.L. Schmidt, J.T. Falgout, B. Williams, N.M. Fairaux, M.K. Caldwell, J.J. Picotte, S.M. Howard, S. Stitt, \& J.L. Dwyer. 2017. Mapping burned areas using dense time-series of Landsat data. Remote Sensing of Environment, 198: 504-522. doi: 10.1016/j.rse.2017.06.027

Healey, S.P., W.B. Cohen, Y. Zhiqiang, \& O.N. Krankina. 2005. Comparison of Tasseled Cap-based Landsat data structures for use in forest disturbance detection. Remote Sensing of Environment, 97(3): 301-310. doi: 10.1016/j.rse.2005.05.009

Hermosilla, T., M.A. Wulder, J.C. White, N.C. Coops, \& G.W. Hobart. 2015a. An integrated Landsat time series protocol for change detection and generation of annual gap-free surface reflectance composites. Remote Sensing of Environment, 158: 220-234. doi: 10.1016/j.rse.2014.11.005

Hermosilla, T., M.A. Wulder, J.C. White, N.C. Coops, \& G.W. Hobart. 2015b. Regional detection, characterization, and attribution of annual forest change from 1984 to 2012 using Landsatderived time-series metrics. Remote Sensing of Environment, 170: 121-132. doi: 10.1016/j.rse 2015.09.004

Hermosilla, T., M.A. Wulder, J.C. White, N.C. Coops, G.W. Hobart, \& L.B. Campbell. 2016. Mass data processing of time series Landsat imagery: pixels to data products for forest monitoring. International Journal of Digital Earth, 8947: 1-20. doi: 10.1080/17538947.2016.1187673

Heurich, M., T. Ochs, T. Andresen, \& T. Schneider. 2010. Object-orientated image analysis for the semi-automatic detection of dead trees following a spruce bark beetle (Ips typographus) outbreak. European Journal of Forest Research, 129(3): 313-324. doi: 10.1007/s10342-009-0331-1

$\mathrm{Hu}, \mathrm{C}$. 2009. A novel ocean color index to detect floating algae in the global oceans. Remote Sensing of Environment, 113(10): 2118-2129. doi: 10.1016/j.rse.2009.05.012

Huete, A.R., H.Q. Liu, K. Batchily, \& W. van Leeuwen. 1997. A comparison of vegetation indices over a global set of TM images for EOS-MODIS. Remote Sensing of Environment, 59(3): 440-451. doi: 10.1016/S0034-4257(96)00112-5

Intelligent Robotics Group. 2017. The Ames Stereo Pipeline: NASA's Open Source Automated Stereogrammetry Software. URL: http://byss.arc.nasa.gov/stereopipeline/binaries /asp_book-2.5.2.pdf

Jordan, C.F. 1969. Derivation of leaf-area index from quality of light on the forest floor. Ecology, 50(4): 663-666. doi: 10.2307/1936256

Justice, C.O., L. Giglio, S. Korontzi, J. Owens, J.T. Morisette, D. Roy, J. Descloitres, S. Alleaume, F. Petitcolin, \& Y. Kaufman. 2002. The MODIS fire products. Remote Sensing of Environment, 83(1-2): 244-262. doi: 10.1016/s0034-4257(02)00076-7

Justice, C.O., E. Vermote, J.R.G. Townshend, R. Defries, D.P. Roy, D.K. Hall, V.V Salomonson, J.L. Privette, G. Riggs, A. Strahier, W. Lucht, R.B. Myneni, K. Yuri, S.W. Running, R.R. Nemani, Z. Wan, A.R. Huete, W. Van Leeuwen, R.E. Wolfe, L. Giglio, J. Muller, P. Lewis, \& M.J. Barnsley. 1998. The Moderate Resolution Imaging Spectroradiometer (MODIS): Land remote sensing for global change research. IEEE Transactions on Geoscience and Remote Sensing, 36(4): 1228-1249. doi: $10.1109 / 36.701075$

Kääb, A., T. Bolch, K. Casey, T. Heid, J.S. Kargel, G.J. Leonard, F. Paul \& B.H. Raup. 2014. Glacier mapping and monitoring using multispectral data. In J.S. Kargel, G.J. Leonard, M.P. Bishop, A. Kääb \& B.H. Raup (Eds.), Global Land Ice Measurements from Space (pp. 75-112). Berlin, Heidelberg: Springer Berlin Heidelberg. doi: 10.1007/978-3-540-79818-7_4 
Kääb, A., \& M. Vollmer. 2000. Surface geometry, thickness changes and flow fields on creeping mountain permafrost: Automatic extraction by digital image analysis. Permafrost and Periglacial Processes, 11(4): 315-326. doi: 10.1002/1099-1530(200012)11:4\%3C315::AID -PPP365\%3E3.0.CO;2-J

Kargel, J.S., G.J. Leonard, D.H. Shugar, U.K. Haritashya, A. Bevington, E.J. Fielding, K. Fujita, M. Geertsema, E.S. Miles, et al. 2016. Geomorphic and geologic controls of geohazards induced by Nepal's 2015 Gorkha earthquake. Science, 351(6269): 141-151. doi: 10.1126/science.aac8353

Kaufman, Y.J., C.O. Justice, L.P. Flynn, J.D. Kendall, E.M. Prins, L. Giglio, D.E. Ward, W.P. Menzel, \& A.W. Setzer. 1998. Potential global fire monitoring from EOS-MODIS. Journal of Geophysical Research: Atmospheres, 103(D24): 32215-32238. doi: 10.1029/98jd01644

Key, C.H., \& N.C. Benson. 1999. Measuring and remote sensing of burn severity: the CBI and NBR [Poster]. In Proceedings Joint Fire Science Conference and Workshop (p. 1). Boise, ID.

Key, C.H., \& N.C. Benson. 2006. Landscape Assessment (LA): Sampling and Analysis Methods. In D. C. Lutes, R. E. Keane, J. F. Caratti, C. H. Key, N. C. Benson, S. Sutherland \& L. J. Gangi (Eds.), FIREMON: Fire effects monitoring and inventory system (Gen. Tech., pp. 1-55). Fort Collins, CO: U.S. Department of Agriculture.

Knudby, A., S.K. Ahmad, \& C. Ilori. 2016. The potential for Landsat-based bathymetry in Canada. Canadian Journal of Remote Sensing, 42(4): 367-378. doi: 10.1080/07038992.2016.1177452

Kuenzer, C., S. Dech, \& W. Wagner (Eds.). 2015. Remote Sensing Time Series. Remote Sensing and Digital Image Processing (Vol. 22). Cham: Springer International Publishing. doi: 10.1007/9783-319-15967-6

Lacaux, J.P., Y.M. Tourre, C. Vignolles, J.A. Ndione, \& M. Lafaye. 2007. Classification of ponds from high-spatial resolution remote sensing: Application to Rift Valley Fever epidemics in Senegal. Remote Sensing of Environment, 106(1): 66-74. doi: 10.1016/j.rse.2006.07.012

Lasaponara, R., \& A. Lanorte. 2012. Satellite time-series analysis. International Journal of Remote Sensing, 33(15): 4649-4652. doi: 10.1080/01431161.2011.638342

Latifovic, R., \& D. Pouliot. 2007. Analysis of climate change impacts on lake ice phenology in Canada using the historical satellite data record. Remote Sensing of Environment, 106(4): 492-507. doi: 10.1016/j.rse.2006.09.015

Leprince, S., S. Barbot, F. Ayoub, \& J.P. Avouac. 2007. Automatic, precise, ortho-rectification and coregistration for satellite Image Correlation, Application to Ground Deformation Measurement. IEEE J. Geosci. Rem. Sens., 45(6): 1529-1558. doi: 10.1109/tgrs.2006.888937

Loughlin, W.P. 1991. Principal Component Analysis for mineral alteration mapping. Photogrammetric Engineering and Remote Sensing, 57(9): 1163-1169.

Malenovský, Z., H. Rott, J. Cihlar, M.E. Schaepman, G. García-Santos, R. Fernandes, \& M. Berger. 2012. Sentinels for science: Potential of Sentinel-1, -2 , and -3 missions for scientific observations of ocean, cryosphere, and land. Remote Sensing of Environment, 120: 91-101. doi: 10.1016/j.rse.2011.09.026

McFeeters, S.K. 1996. The use of the Normalized Difference Water Index (NDWI) in the delineation of open water features. International Journal of Remote Sensing, 17(7): 1425-1432. doi: $10.1080 / 01431169608948714$

Meng, J., S. Li, W. Wang, Q. Liu, S. Xie, \& W. Ma. 2016. Mapping forest health using spectral and textural information extracted from SPOT-5 satellite images. Remote Sensing, 8(9): 719-739. doi: $10.3390 / \mathrm{rs} 8090719$

National Aeronautics and Space Administration. (n.d.-a). NASA Worldview. URL: https://worldview .earthdata.nasa.gov (Accessed June 5, 2018).

National Aeronautics and Space Administration. (n.d.-b). Joint Polar Satellite System. URL: https:// jointmission.gsfc.nasa.gov/viirs.html (Accessed June 5, 2018).

National Oceanic and Atmospheric Administration. 2017a. Comprehensive Large Array-Data Stewardship System. URL: https://www.avl.class.noaa.gov/ (Accessed December 1, 2017).

National Oceanic and Atmospheric Administration. 2017b. Advanced Very High Resolution Radiometer. URL: http://noaasis.noaa.gov/NOAASIS/ml/avhrr.html (Accessed June 5, 2018). 
National Snow and Ice Data Center. 2017. Global Land Ice Velocity Extraction from Landsat 8 (GoLIVE), Version 1. URL: http://nsidc.org/data/nsidc-0710 (Accessed December 1, 2017).

Neteler, M., M.H. Bowman, M. Landa, \& M. Metz. 2012. GRASS GIS: A multi-purpose open source GIS. Environmental Modelling and Software, 31: 124-130. doi: 10.1016/j.envsoft.2011.11.014

Olthof, I. 2017. Mapping seasonal inundation frequency (1985-2016) along the St-John River, New Brunswick, Canada using the Landsat archive. Remote Sensing, 9(2): 143-159. doi: 10.3390 /rs9020143

Page, B.P., A. Kumar, \& D.R. Mishra. 2018. A novel cross-satellite based assessment of the spatiotemporal development of a cyanobacterial harmful algal bloom. International Journal of Applied Earth Observation and Geoinformation, 66(October 2017): 69-81. doi: 10.1016/j.jag.2017.11.003

Parajka, J., M. Pepe, A. Rampini, S. Rossi, \& G. Blöschl. 2010. A regional snow-line method for estimating snow cover from MODIS during cloud cover. Journal of Hydrology, 381(3-4): 203-212. doi: 10.1016/j.jhydrol.2009.11.042

Pekel, J.-F., A. Cottam, N. Gorelick, \& A.S. Belward. 2016. High-resolution mapping of global surface water and its long-term changes. Nature, 342(6160): 850-853. doi: 10.1038/nature20584

Peng, J., \& A. Loew. 2017. Recent advances in soil moisture estimation from remote sensing. Water, 9(7): 530-534. doi: 10.3390/w9070530

Phiri, D., \& J. Morgenroth. 2017. Developments in Landsat land cover classification methods: A review. Remote Sensing, 9(9): 967-992. doi: 10.3390/rs9090967

Planet. (n.d.). Planet Explorer. URL: https://www.planet.com/explorer (Accessed June 5, 2018).

Polar Geospatial Center. 2017. ArcticDEM. URL: https://www.pgc.umn.edu/data/arcticdem/ (Accessed December 1, 2017).

Popkin, G. 2018. US Government considers changing for popular earth-observing data. Nature 556: 417-418. doi: 10.1038/d41586-018-04874-y

QGIS Development Team. 2012. QGIS Geographic Information System. Open Source Geospatial Foundation Project. URL: https://docs.qgis.org/2.18/en/docs/user_manual/ (Accessed July 3, 2018).

Raup, B., A. Racoviteanu, S.J.S. Khalsa, C. Helm, R. Armstrong, \& Y. Arnaud. 2007. The GLIMS geospatial glacier database: A new tool for studying glacier change. Global and Planetary Change, 56(1-2): 101-110. doi: 10.1016/j.gloplacha.2006.07.018

Rouse, J.W., R.H. Haas, J.A. Schell, \& D.W. Deering. 1973. Monitoring vegetation systems in the great plains with ERTS. In: Third ERTS symposium, NASA SP-351, vol. 1, pp. 309-317. Washington, D.C.: U.S. Government Printing Office.

Roy, D.P., M.A. Wulder, T.R. Loveland, C.E. Woodcock, R.G. Allen, M.C. Anderson, D. Helder, J.R. Irons, D.M. Johnson, R. Kennedy, T.A. Scambos, C.B. Schaaf, J.R. Schott, Y. Sheng, E.F. Vermote, A.S. Belward, R. Bindschadler, W.B. Cohen, F. Gao, J.D. Hipple, P. Hostert, J. Huntington, C.O. Justice, A. Kilic, V. Kovalskyy, Z.P. Lee, L. Lymburner, J.G. Masek, J. McCorkel, Y. Shuai, R. Trezza, J. Vogelmann, R.H. Wynne, \& Z. Zhu. 2014. Landsat-8: Science and product vision for terrestrial global change research. Remote Sensing of Environment, 145: 154-172. doi: 10.1016/j.rse.2014.02.001

Sadeghi, M., E. Babaeian, M. Tuller, \& S.B. Jones. 2017. The optical trapezoid model: A novel approach to remote sensing of soil moisture applied to Sentinel-2 and Landsat-8 observations. Remote Sensing of Environment, 198: 52-68. doi: 10.1016/j.rse.2017.05.041

Sarago, V. (n.d.). RemotePixel. URL: https://remotepixel.ca (Accessed June 5, 2018).

Scambos, T.A., M.J. Dutkiewicz, J.C. Wilson, \& R.A. Bindschadler. 1992. Application of image crosscorrelation to the measurement of glacier velocity using satellite image data. Remote Sensing of Environment, 42(3): 177-186. doi: 10.1016/0034-4257(92)90101-o

Schmugge, T., S.J. Hook, \& C. Coll. 1998. Recovering surface temperature and emissivity from thermal infrared multispectral data. Remote Sensing of Environment, 65(2): 121-131. doi: $10.1016 / \mathrm{s} 0034-4257(98) 00023-6$ 
Schroeder, W., P. Oliva, L. Giglio, \& I.A. Csiszar. 2014. The new VIIRS 375m active fire detection data product: Algorithm description and initial assessment. Remote Sensing of Environment, 143: 85-96. doi: 10.1016/j.rse.2013.12.008

Shean, D. 2017. High mountain Asia 8-meter DEM mosaics derived from optical imagery, Version 1. doi: 10.5067/KXOVQ9L172S2

Tachikawa, T., M. Hato, M. Kaku and A. Iwasaki. 2011. Characteristics of ASTER GDEM version 2., 3657-3660. Vancouver, BC.: IEEE International Geoscience and Remote Sensing Symposium. doi: 10.1109/IGARSS.2011.6050017

Takaku, J., T. Tadono, \& K. Tsutsui. 2014. Generation of high resolution global DSM from ALOS PRISM. International Archives of the Photogrammetry, Remote Sensing and Spatial Information Sciences - ISPRS Archives, 40(4): 243-248. doi: 10.5194/isprsarchives-xl-4-243-2014

Tan, H. 2008. ASTER SWIR Alert. URL: https://asterweb.jpl.nasa.gov/swir-alert.asp (Accessed October 18, 2017).

Toutin, T. 2001. Elevation modelling from satellite visible and infrared (VIR) data. International Journal of Remote Sensing, 22(6): 1097-1125. doi: 10.1080/014311601300074649

Ungar, S.G., J.S. Pearlman, J.A. Mendenhall, \& D. Reuter. 2003. Overview of the Earth Observing One (EO-1) mission. IEEE Transactions on Geoscience and Remote Sensing, 41(6): 1149-1159. doi: $10.1109 /$ tgrs.2003.815999

United States Geological Survey. (n.d.-a). LandsatLook. URL: https://landsatlook.usgs.gov (Accessed June 5, 2018).

United States Geological Survey. (n.d.-b). Sentinel2Look. URL: https://landsatlook.usgs.gov/sentinel2 (Accessed June 5, 2018).

United States Geological Survey. 2017a. USGS EarthExplorer. URL: https://earthexplorer.usgs.gov/ (Accessed December 1, 2017).

United States Geological Survey. 2017b. Landsat Missions. URL: https://landsat.usgs.gov/what-arebest-spectral-bands-use-my-study (Accessed December 1, 2017).

Verbyla, D., T. Hegel, A. Nolin, M. van de Kerk, T. Kurkowski, \& L. Prugh. 2017. Remote sensing of 2000-2016 alpine spring snowline elevation in dall sheep mountain ranges of Alaska and Western Canada. Remote Sensing, 9(11): 1157-1175. doi: 10.3390/rs9111157

Web of Knowledge. 2017. Web of Science. URL: https://webofknowledge.com/ (Accessed December 1, 2017).

Weng, Q. 2009. Thermal infrared remote sensing for urban climate and environmental studies: Methods, applications, and trends. ISPRS Journal of Photogrammetry and Remote Sensing, 64(4): 335-344. doi: 10.1016/j.isprsjprs.2009.03.007

White, J.C., N.C. Coops, M.A. Wulder, M. Vastaranta, T. Hilker, \& P. Tompalski. 2016. Remote sensing technologies for enhancing forest inventories: a review. Canadian Journal of Remote Sensing, 42(5): 619-641. doi: 10.1080/07038992.2016.1207484

White, J.C., M.A. Wulder, G.W. Hobart, J.E. Luther, T. Hermosilla, P. Griffiths, N.C. Coops, R.J. Hall, P. Hostert, A. Dyk, \& L. Guindon. 2014. Pixel-based image compositing for large-area dense time series applications and science. Canadian Journal of Remote Sensing, 40(3): 192-212. doi: 10.1080/07038992.2014.945827

Woodcock, C., R. Allen, M. Anderson, A. Belward, R. Bindschadler, C. Warren, F. Gao, S.N. Goward, D. Helder, E. Helmer, R. Nemani, L. Oreopoulos, J. Schott, P.S. Thenkabail, E.F. Vermote, J. Vogelmann, M.A. Wulder, \& R. Wynne. 2008. Free access to Landsat imagery. Science, 320(5879): 1011-1012. doi: 10.1126/science.320.5879.1011a

Wooster, M.J., W. Xu, \& T. Nightingale. 2012. Sentinel-3 SLSTR active fire detection and FRP product: Pre-launch algorithm development and performance evaluation using MODIS and ASTER datasets. Remote Sensing of Environment, 120: 236-254. doi: 10.1016/j.rse.2011.09.033

World Meteorological Organization. 2016. OSCAR: Observing Systems Capability Analysis and Review tool. URL: https://www.wmo-sat.info/oscar/satellites (Accessed November 20, 2016). 
Xie, Y., Z. Sha, \& M. Yu. 2008. Remote sensing imagery in vegetation mapping: a review. Journal of Plant Ecology, 1(1): 9-23. doi: 10.1093/jpe/rtm005

$\mathrm{Xu}, \mathrm{H} .2006$. Modification of normalised difference water index (NDWI) to enhance open water features in remotely sensed imagery. International Journal of Remote Sensing, 27(14): 3025-3033. doi: 10.1080/01431160600589179

Yilmaz, M.T., E.R. Hunt, \& T.J. Jackson. 2008. Remote sensing of vegetation water content from equivalent water thickness using satellite imagery. Remote Sensing of Environment, 112(5): 2514-2522. doi: 10.1016/j.rse.2007.11.014

Zhao, F.R., R. Meng, C. Huang, M. Zhao, F.A. Zhao, P. Gong, L. Yu, \& Z. Zhu. 2016. Long-term postdisturbance forest recovery in the greater yellowstone ecosystem analyzed using Landsat time series stack. Remote Sensing, 8(898): 1-22. doi: 10.3390/rs8110898

Zhu, Z., S. Wang, \& C.E. Woodcock. 2015. Improvement and expansion of the Fmask algorithm: cloud, cloud shadow, and snow detection for Landsats 4-7, 8, and Sentinel 2 images. Remote Sensing of Environment, 159: 269-277. doi: 10.1016/j.rse.2014.12.014

Zhu, Z., \& C.E. Woodcock. 2014. Continuous change detection and classification of land cover using all available Landsat data. Remote Sensing of Environment, 144: 152-171. doi: 10.1016/j.rse .2014.01.011

Zhu, Z., C.E. Woodcock, \& P. Olofsson. 2012. Continuous monitoring of forest disturbance using all available Landsat imagery. Remote Sensing of Environment, 122: 75-91. doi:

10.1016/j.rse.2011.10.030 


\section{Appendix A}

\section{Free Online Visualization Tools}

\begin{tabular}{|c|c|c|c|c|c|}
\hline Webpage & Parameters & Sensors & Coverage & Description & Reference \\
\hline LandsatLook & $\mathrm{G} / \mathrm{FA} / \mathrm{CR} / \mathrm{FC} / \mathrm{CD} / \mathrm{T}$ & LS & $1972-2018$ & $\begin{array}{l}\text { USGS platform to view } \\
\text { imagery }\end{array}$ & (United States Geological Survey, n.d.-a) \\
\hline Sentinel2Look & $\mathrm{G} / \mathrm{FA} / \mathrm{CR} / \mathrm{FC} / \mathrm{CD} / \mathrm{T}$ & S2 & 2015-2018 & $\begin{array}{l}\text { USGS platform to view } \\
\text { imagery }\end{array}$ & (United States Geological Survey, n.d.-b) \\
\hline $\begin{array}{l}\text { Google Earth Engine } \\
\text { Explorer }\end{array}$ & G/FA/FR/CC/GD & LS/MOD & 1984-2018 & $\begin{array}{l}\text { Google platform to view } \\
\text { and process imagery }\end{array}$ & (Google, n.d.-a) \\
\hline Google Timelapse & G/AA/CR/TC/ND/T & LS & 1984-2016 & Global Timelapse & (Google, n.d.-b) \\
\hline $\begin{array}{l}\text { Google Timelapse } \\
\text { Editor }\end{array}$ & G/AA/CR/TC/ ND/T & LS & 1984-2016 & $\begin{array}{l}\text { Customization tools for } \\
\text { Google Timelapse }\end{array}$ & (Carnegie Mellon Create Lab, n.d.) \\
\hline $\begin{array}{l}\text { Sentinel Hub } \\
\text { Playgound }\end{array}$ & $\mathrm{G} / \mathrm{FA} / \mathrm{FR} / \mathrm{CC} / \mathrm{CD}$ & S2/LS/MOD & 2013-2018 & $\begin{array}{l}\text { ESA platform to view } \\
\text { imagery }\end{array}$ & (European Space Agency, n.d.-a) \\
\hline EO Browser & $\mathrm{G} / \mathrm{FA} / \mathrm{FR} / \mathrm{CC} / \mathrm{GD} / \$$ & $\begin{array}{l}\mathrm{S} 1 / \mathrm{S} 2 / \mathrm{S} 3 / \mathrm{LS} / \\
\mathrm{MOD} / \mathrm{ES} / \mathrm{PV}\end{array}$ & 2013-2018 & $\begin{array}{l}\text { ESA platform to view } \\
\text { imagery }\end{array}$ & (European Space Agency, n.d.-b) \\
\hline NASA Worldview & G/FA/FR/CC/GD/T/M & MOD/VIIRS & 2003-2018 & $\begin{array}{l}\text { NASA platform to view } \\
\text { imagery }\end{array}$ & $\begin{array}{l}\text { (National Aeronautics and Space } \\
\text { Administration, n.d.-a) }\end{array}$ \\
\hline RemotePixel & G/FA/FR/CC/GD/T/M & LS/MOD/S2 & 2013-2018 & $\begin{array}{l}\text { Independent Canadian } \\
\text { platform for searching } \\
\text { and visualizing imagery }\end{array}$ & (Sarago, n.d.) \\
\hline Planet Explorer & G/FA/CR/TC/ND/T/\$ & PS/RE/LS/S2 & 2010-2018 & $\begin{array}{l}\text { Commercial platform to } \\
\text { view global } 3 \mathrm{~m} \text { mosaics }\end{array}$ & (Planet, n.d.) \\
\hline
\end{tabular}

Notes: Parameters: $\mathrm{G}=$ Global; FA = Full Archive, $\mathrm{AA}=$ Annual Archive; CR = Compressed Resolution, FR = Full-Resolution; TC = True Colour, $\mathrm{FC}=$ False Colour, $\mathrm{CC}=$ Custom Composite; GD = Full Geotiff Download, $\mathrm{CD}=$ Compressed Image Download, ND = No Download; $\mathrm{T}=\mathrm{Timelapse}$ Tool, M = Movie Export; \$ = Additional Pay Features. Sensors: LS = Landsat Archive, S1 = Sentinel-1, S2 = Sentinel-2, S3 = Sentinel-3, MOD = MODIS, $\mathrm{ES}=$ Envisat Meris, $\mathrm{PV}=\mathrm{PROBAV}, \mathrm{VIIRS}=$ Suomi, $\mathrm{PS}=$ PlanetScope, $\mathrm{RE}=$ RapidEye 


\section{Appendix B}

\section{Free and Open Source Remote Sensing Software}

\begin{tabular}{|c|c|c|}
\hline Name & Description & Reference \\
\hline QGIS & GIS software with raster processing capabilities & (QGIS Development Team, 2012) \\
\hline $\begin{array}{l}\text { QGIS and Semi-Automatic } \\
\text { Classification (SCP) Plugin }\end{array}$ & QGIS plugin to search, download, process, and classify satellite imagery & (Congedo, 2017) \\
\hline ESA SNAP Toolbox & Fully functional remote sensing capabilities for optical and radar imagery & (European Space Agency, 2017b) \\
\hline Google Earth Engine Code Editor & Cloud-based coding platform for processing FOSI at global scales & (Gorelick et al., 2017) \\
\hline SAGA & GIS software with raster processing capabilities & (Conrad et al., 2015) \\
\hline GRASS & GIS software with raster processing capabilities & (Neteler et al., 2012) \\
\hline OTB & Tools for processing of remote sensing images & (Christophe et al., 2008) \\
\hline
\end{tabular}

\section{Appendix $\mathrm{C}$}

\section{Free Remote Sensing Products}

\begin{tabular}{|c|c|c|}
\hline Product Name & Dataset Description & Reference \\
\hline Global Forest Cover Change & View and download global $30 \mathrm{~m}$ resolution forest cover data (2000-2016) & (Hansen et al. 2013) \\
\hline Global Surface Water Explorer & View and download global $30 \mathrm{~m}$ resolution water occurrence (1984-2015) & (Pekel et al., 2016) \\
\hline $\begin{array}{l}\text { Satellite Forest Monitoring in } \\
\text { Canada }\end{array}$ & View Canadian $30 \mathrm{~m}$ resolution forest cover change attribution (1985-2011) & $\begin{array}{l}\text { (Hermosilla et al., 2015a, 2015b, } \\
\text { 2016; White et al., 2014) }\end{array}$ \\
\hline Global Land Cover "Glob30" & View and download global $30 \mathrm{~m}$ land cover classes (2000 \& 2010) & (Chen et al., 2015) \\
\hline Global Land Cover Facility & Useful collection of many global land cover datasets & (e.g., Hansen et al., 2000) \\
\hline $\begin{array}{l}\text { MODIS and VIIRS Active Fire for } \\
\text { Google Earth }\end{array}$ & View and download global active fire-mapping layers & $\begin{array}{l}\text { (Justice et al., 2002; Kaufman et al., } \\
\text { 1998) }\end{array}$ \\
\hline ASTER GDEM & Download a global $30 \mathrm{~m}$ DEM & (Tachikawa et al., 2011) \\
\hline ALOS World 3D & Download global 30 m DEM & (Takaku et al., 2014) \\
\hline ArcticDEM & View and download circumpolar high-resolution DEM & (Polar Geospatial Center, 2017) \\
\hline $\begin{array}{l}\text { Global Land Ice Velocity Extraction } \\
\text { from Landsat }\end{array}$ & Download glacier velocity vectors & $\begin{array}{l}\text { (National Snow and Ice Data } \\
\text { Center, 2017) }\end{array}$ \\
\hline $\begin{array}{l}\text { Global Land Ice Measurements } \\
\text { from Space (GLIMS) }\end{array}$ & View and download glacier outlines & (Raup et al., 2007) \\
\hline
\end{tabular}




\section{Appendix D}

\section{Low-Resolution Satellite Sensors}

\begin{tabular}{|c|c|c|c|c|c|}
\hline Satellite & Sensor, Agency & $\begin{array}{l}\text { Spectral Bands } \\
\text { (Spatial } \\
\text { Resolution) }\end{array}$ & $\begin{array}{l}\text { Revisit, Swath, } \\
\text { Radiometric } \\
\text { Resolution }\end{array}$ & Operational Lifetime & Comments and References \\
\hline $\begin{array}{l}\text { TIROS-N } \\
\text { NOAA 6-19 } \\
\text { MetOp A } \\
\text { and B }\end{array}$ & $\begin{array}{l}\text { Advanced Very } \\
\text { High-Resolution } \\
\text { Radiometer } \\
\text { (AVHRR 1-3) } \\
\text { NASA/NOAA }\end{array}$ & $\begin{array}{l}\operatorname{VIS}(1,000 \mathrm{~m}) \\
\operatorname{NIR}(1,000 \mathrm{~m}) \\
\operatorname{TIR}(1,000 \mathrm{~m})\end{array}$ & $\begin{array}{l}\text { Daily, } \\
\text { 2,900 km, } \\
\text { 10-bit }\end{array}$ & $\begin{array}{l}\text { AVHRR-1 Oct 1978-Sep } 1991 \\
\text { AVHRR-2 Aug 1981- May } 2007 \\
\text { AVHRR-3 May 1998- present }\end{array}$ & $\begin{array}{l}\text { The AVHRR sensors represent a highly } \\
\text { accessible data collection system with } \\
\text { applications in meteorology, climatology, } \\
\text { oceanography, and land surface processes. } \\
\text { The AVHRR is an important resource in } \\
\text { weather forecasting (National Oceanic and } \\
\text { Atmospheric Administration, 2017b). }\end{array}$ \\
\hline $\begin{array}{l}\text { Terra and } \\
\text { Aqua }\end{array}$ & $\begin{array}{l}\text { Moderate } \\
\text { Resolution } \\
\text { Imaging } \\
\text { Spectroradio- } \\
\text { meter (MODIS) } \\
\text { NASA }\end{array}$ & $\begin{array}{l}\operatorname{VIS}(250 / 500 \mathrm{~m}) \\
\operatorname{NIR}(1,000 \mathrm{~m}) \\
\operatorname{SWIR}(1,000 \mathrm{~m}) \\
\operatorname{TIR}(1,000 \mathrm{~m})\end{array}$ & $\begin{array}{l}\text { Daily, } \\
\text { 2,330 km, } \\
\text { 12-bit }\end{array}$ & $\begin{array}{l}\text { MODIS Terra Dec } 1999-\text { present } \\
\text { MODIS Aqua May 2002- present }\end{array}$ & $\begin{array}{l}\text { The MODIS 36-channel sensor was } \\
\text { designed to provide daily coverage of land, } \\
\text { ocean, and atmospheric processes at a } \\
\text { global scale. MODIS represents an } \\
\text { important archive of environmental } \\
\text { change (Justice et al., 1998). }\end{array}$ \\
\hline $\begin{array}{l}\text { Suomi NPP } \\
\text { and NOAA } \\
20\end{array}$ & $\begin{array}{l}\text { Visible Infrared } \\
\text { Imaging } \\
\text { Radiometer } \\
\text { Suite (VIIRS) } \\
\text { NASA/NOAA }\end{array}$ & $\begin{array}{l}\operatorname{VIS}(375 / 750 \mathrm{~m}) \\
\operatorname{NIR}(375 / 750 \mathrm{~m}) \\
\operatorname{SWIR}(375 / 750 \mathrm{~m}) \\
\operatorname{TIR}(375 / 750 \mathrm{~m})\end{array}$ & $\begin{array}{l}\text { Daily, } \\
\text { 3,000 km, } \\
\text { 12-bit }\end{array}$ & $\begin{array}{l}\text { Suomi NPP VIIRS } \\
\text { Oct } 2011 \text { - present } \\
\text { NOAA } 20 \text { VIIRS } \\
\text { Nov } 2017 \text { - present }\end{array}$ & $\begin{array}{l}\text { This NASA/NOAA partnership intended } \\
\text { to improve the measurements of AVHRR } \\
\text { and MODIS for future Joint Polar Satellite } \\
\text { System (JPSS) satellites. The JPSS satellites } \\
\text { are very useful for monitoring natural } \\
\text { disasters (National Aeronautics and Space } \\
\text { Administration, n.d.-b). }\end{array}$ \\
\hline Sentinel-3A & $\begin{array}{l}\text { Ocean and Land } \\
\text { Colour Instru- } \\
\text { ment (OLCI) } \\
\text { ESA }\end{array}$ & $\begin{array}{l}\operatorname{VIS}(300 \mathrm{~m}) \\
\operatorname{NIR}(300 / 500 \mathrm{~m}) \\
\operatorname{SWIR}(500 \mathrm{~m}) \\
\operatorname{TIR}(1,000 \mathrm{~m})\end{array}$ & $\begin{array}{l}<4 \text { Days, } \\
1,270 \mathrm{~km}, \\
12 \text {-bit }\end{array}$ & S3A OLCI Feb 2016 - present & $\begin{array}{l}\text { The OLCI instrument serves as a continu- } \\
\text { ation of the Medium Resolution Imaging } \\
\text { Spectrometer (MERIS) sensor, providing } \\
\text { information about ocean surface topogra- } \\
\text { phy as well as land and sea surface temper- } \\
\text { ature (Malenovský et al., 2012). }\end{array}$ \\
\hline
\end{tabular}

Note: Spectral bands are represented as broad categories; see Figure 2 for detailed spectral ranges. 


\section{Appendix E}

\section{Medium-Resolution Satellite Sensors}

\begin{tabular}{|c|c|c|c|c|c|}
\hline Satellite & $\begin{array}{l}\text { Sensor, } \\
\text { Agency }\end{array}$ & $\begin{array}{l}\text { Spectral Bands } \\
\text { (Spatial } \\
\text { Resolution) }\end{array}$ & $\begin{array}{l}\text { Revisit, } \\
\text { Swath, } \\
\text { Radiometric } \\
\text { Resolution }\end{array}$ & Operational Lifetime & Comments and References \\
\hline EO-1 & $\begin{array}{l}\text { Advanced } \\
\text { Land Imager } \\
\text { (ALI) NASA }\end{array}$ & $\begin{array}{l}\text { PAN }(10 \mathrm{~m}) \\
\text { VIS }(30 \mathrm{~m}) \\
\text { NIR }(30 \mathrm{~m}) \\
\text { SWIR }(30 \mathrm{~m})\end{array}$ & $\begin{array}{l}16 \text { days, } \\
185 \mathrm{~km}, \\
12 \text {-bit }\end{array}$ & EO-1 Nov 2000-Feb 2017 & $\begin{array}{l}\text { EO-1 ALI was an experimental satellite sensor with } \\
\text { very sparse data acquisition (Ungar et al., 2003). }\end{array}$ \\
\hline Landsat 1-3 & $\begin{array}{l}\text { Multispectral } \\
\text { Scanner } \\
\text { (MSS) NASA }\end{array}$ & $\begin{array}{l}\text { VIS }(60 \mathrm{~m}) \\
\text { NIR }(60 \mathrm{~m})\end{array}$ & $\begin{array}{l}18 \text { days, } \\
185 \mathrm{~km}, \\
6 \text {-bit }\end{array}$ & $\begin{array}{l}\text { L1 MSS Jul 1972-Jan } 1975 \\
\text { L2 MSS Mar 1978-Jan } 1978 \\
\text { L3 MSS Feb 1982- Mar } 1983\end{array}$ & $\begin{array}{l}\text { Landsat 1-3 MSS provide a global window into the } \\
\text { 1970s and early 1980s (United States Geological } \\
\text { Survey, 2017b). }\end{array}$ \\
\hline Landsat $4-5$ & $\begin{array}{l}\text { Thematic } \\
\text { Mapper (TM) } \\
\text { NASA }\end{array}$ & $\begin{array}{l}\text { VIS }(30 \mathrm{~m}) \\
\operatorname{NIR}(30 \mathrm{~m}) \\
\text { SWIR }(30 \mathrm{~m}) \\
\operatorname{TIR}(120 \mathrm{~m})\end{array}$ & $\begin{array}{l}18 \text { days, } \\
185 \mathrm{~km}, \\
8 \text {-bit }\end{array}$ & $\begin{array}{l}\text { L4 MSS / TM Jul 1982-Mar } 1984 \\
\text { L5 MSS / TM Dec 1993-Jun } 2013\end{array}$ & $\begin{array}{l}\text { Landsat 4-5 TM provide continuous } 30 \mathrm{~m} \text { resolu- } \\
\text { tion imagery over the globe between } 1982-2013 \text {, } \\
\text { but more reliably between 1985-2012 (United States } \\
\text { Geological Survey, 2017b). }\end{array}$ \\
\hline Landsat 7 & $\begin{array}{l}\text { Enhanced } \\
\text { Thematic } \\
\text { Mapper } \\
\text { (ETM+) } \\
\text { NASA }\end{array}$ & $\begin{array}{l}\text { PAN }(15 \mathrm{~m}) \\
\text { VIS }(30 \mathrm{~m}) \\
\text { NIR }(30 \mathrm{~m}) \\
\text { SWIR }(30 \mathrm{~m}) \\
\text { TIR }(120 \mathrm{~m})\end{array}$ & $\begin{array}{l}16 \text { days, } \\
185 \mathrm{~km}, \\
\text { 9-bit }\end{array}$ & L7 ETM+ Apr 1999-present & $\begin{array}{l}\text { Issues began in } 2003 \text { affecting the scan line } \\
\text { corrector (SLC). Since May 1,2003, persistent black } \\
\text { stripes compromise }>20 \% \text { of each image (United } \\
\text { States Geological Survey, 2017b). }\end{array}$ \\
\hline Landsat 8 & $\begin{array}{l}\text { Operational } \\
\text { Land Imager } \\
(\text { OLI }) \\
\text { NASA }\end{array}$ & $\begin{array}{l}\text { PAN }(15 \mathrm{~m}) \\
\text { VIS }(30 \mathrm{~m}) \\
\text { NIR }(30 \mathrm{~m}) \\
\text { SWIR }(30 \mathrm{~m}) \\
\text { TIR }(100 \mathrm{~m})\end{array}$ & $\begin{array}{l}16 \text { days, } \\
185 \mathrm{~km}, \\
12 \text {-bit }\end{array}$ & L8 OLI Feb 2013-present & $\begin{array}{l}\text { Landsat } 8 \text { OLI provides many enhancements to the } \\
\text { ETM+, most notably the 12-bit radiometry and the } \\
\text { addition of coastal and cirrus bands (United States } \\
\text { Geological Survey, 2017b). }\end{array}$ \\
\hline Terra & $\begin{array}{l}\text { Advanced } \\
\text { Spaceborne } \\
\text { Thermal } \\
\text { Emission and } \\
\text { Reflection } \\
\text { Radiometer } \\
\text { (ASTER) } \\
\text { JAXA/NASA }\end{array}$ & $\begin{array}{l}\text { VIS }(15 \mathrm{~m}) \\
\operatorname{NIR}(15 \mathrm{~m}) \\
\operatorname{SWIR}(15 \mathrm{~m}) \\
\operatorname{TIR}(90 \mathrm{~m})\end{array}$ & $\begin{array}{l}16 \text { days, } \\
60 \mathrm{~km}, \\
8 \text {-bit } \\
(12 \text {-bit TIR) }\end{array}$ & ASTER Dec 1999-present & $\begin{array}{l}\text { The SWIR bands were decommissioned on April 1, } \\
\text { 2008, because of anomalously high SWIR values } \\
\text { indicative of instrumentation error (Tan, 2008). }\end{array}$ \\
\hline $\begin{array}{l}\text { Sentinel } 2 \mathrm{~A} \\
\text { and } 2 \mathrm{~B}\end{array}$ & $\begin{array}{l}\text { Multispectral } \\
\text { Imager (MSI) } \\
\text { ESA }\end{array}$ & $\begin{array}{l}\text { VIS }(10 \mathrm{~m}) \\
\operatorname{NIR}(10 \mathrm{~m}) \\
\operatorname{SWIR}(20 \mathrm{~m})\end{array}$ & $\begin{array}{l}10 \text { days, } \\
290 \mathrm{~km}, \\
12 \text {-bit }\end{array}$ & $\begin{array}{l}\text { S2A MSI Jun 2015- present } \\
\text { S2B MSI Mar 2017- present }\end{array}$ & $\begin{array}{l}\text { Twin polar orbiting satellites phased at } 180^{\circ} \text { to } \\
\text { each other have a combined five-day revist time } \\
\text { (Malenovský et al., 2012). }\end{array}$ \\
\hline
\end{tabular}

Note: Spectral bands are represented as broad categories; see Figure 2 for detailed spectral ranges. 